\title{
On the Benefits of Assortment-based Cooperation Among Independent Producers
}

\author{
Yalçın Akçay \\ College of Administrative Sciences and Economics, Koç University, Rumeli Feneri Yolu, Istanbul, Turkey, 34450, \\ yakcay@ku.edu.tr Phone: +90 2123381560 Fax: +90212 3381653 \\ Barış Tan \\ College of Administrative Sciences and Economics, Koç University, Rumeli Feneri Yolu, Istanbul, Turkey, 34450, \\ Email: btan@ku.edu.tr Phone: +90 2123381459 Fax: +90 2123381653
}

\begin{abstract}
Motivated by the challenges small-to-medium size companies face in export-oriented industries, we consider a competitive market for a set of substitutable products. Depending on the assortment of the firm and the substitution behavior of the customer, either a product is sold to the customer or the sales is lost. We consider the cooperation of independent producers which offer a combined set of products to their customers. Producers use discounted price contracts to manage the exchange of products among themselves. We propose an analytical model that enables us to determine the characteristics of firms and their products that would facilitate a beneficial cooperation. We conclude that a cooperation between symmetric single-product firms is always beneficial, whereas threshold-type criteria should be satisfied so that assortment-based cooperation is beneficial for asymmetric firms. We also show that commonality in product assortments of cooperating firms has adverse effects on the benefit from cooperation. For the most general problem setting, we propose a method to determine the set of firms that should cooperate and set the parameters of the contract among the members of cooperation in such a way that each member of the cooperation is better off. We use a numerical study to draw insights on the conditions for which our cooperation scheme is beneficial in the most general problem setting.
\end{abstract}

Key words: cooperation, network organizations, customer choice, assortment pooling

Submission and Acceptance: Received January 2007; revisions received October 2007 and February 2008; accepted March 2008

\section{Introduction}

As global competition increases, producers with limited resources are searching for new business models to improve their competitiveness and profitability. In situations which do not allow them to achieve these goals on their own, they seek to join forces with competitors. In fact, cooperations 
among competitors are widely believed to make strategic sense due to possible cost reductions, demand pooling effects, capacity utilization benefits and improved flexibility against uncertainty in the business environment. The prospects of this business model looks to excel with the anticipation that the more companies operate and profit together, the more they will gain a vested interest in preserving and cementing these bonds (Sulzer 2001). Our study is motivated from such a situation in the textile and apparel industry. In this industry, large buyers procure from many small- to medium size enterprizes (SMEs) that produce textile and apparel goods all over the world. Given the array of alternative sources, prices are usually set by buyers, and SMEs compete fiercely to collect orders. In order to gain competitive advantage in global markets, a number of small- to medium-size companies can form what is called a network organization to benefit from pooling various activities. A network organization is known as a temporary cooperation of a group of independent companies to benefit from an opportunity in a market that neither of the firms can exploit on their own (Van Alstyne 1997). Examples of such network organizations indeed exist in Italy (Johnston and Lawrence 1988, Kumar et al. 1996), and in Turkey (Ghemawat and Foley 1998). In these cases, network organizations cooperate in their support activities such as IT, human resources, accounting. They also purchase raw materials together, coordinate their logistics and export activities. Moreover they coordinate their sales and marketing activities and pool their capacity to produce orders they receive. Although our work is primarily motivated by applications in production, similar organizations are also observed in many other industries such as agriculture (Mezgár et al. 2000), cargo transportation (Ergun et al. 2007), and airlines (Park 1997, Lin 2004).

In our paper, we present an analytical model to study what we refer to as an assortment-based cooperation among independent producers constituting a network organization. In this setting, a group of companies produce a specific set of products, defined as their assortments. For example, producers in textile industry specialize in the production of certain types of fabric, and hence construct their assortments accordingly. Each producer engages in sales activities to reach their customers, which are mainly large international buyers, so as to generate demand traffic and succeed in realizing customer orders. Depending on the favorite product choice of a potential 
buyer and the assortment of the producer, one of the following three scenarios can be realized; the producer's assortment includes the product choice of the customer, hence order is received; or the producer's assortment does not include the product choice of the customer, but the customer is willing to substitute with another product in the producer's assortment, hence order is received; or the producer's assortment does not include the product choice of the customer and the customer is not willing to substitute with another product in the producer's assortment, hence the sales opportunity is lost. As a result, only a portion of the demand traffic from buyers is translated into actual sales while a portion is lost due to the mismatch between the producer's assortment and the buyer's choice characteristics.

In our problem context, an assortment-based cooperation is formed when a group of producers agree to combine their product assortments and each firm is able to offer this combined assortment to their own customers. Accordingly, when a customer inquires for a certain product, the order is fulfilled when this product is either available in the assortment of the producer itself, the assortment of another producer in the cooperation, or the customer is ready to substitute with a product in the combined assortment. The benefits of this new business model is not transparent because of the trade-off between increased demand traffic from buyers and reduced overall substitution to the firm's own assortment. In other words, one can not trivially foresee the extent of gain/loss scenarios for a particular producer, by the amount of demand directed from the producer towards the competitor firms' products, and the orders directed towards the producer from the other members of the cooperation. Moreover, in the case that there is a mismatch between the buyer's choice and a producer's assortment, the producer can still receive an order if the buyer decides to substitute. However, the frequency of such orders might be reduced, since some portion of these orders will be lost to the cooperating competitors' products. In such intricate dynamics, a number of research questions arise: Is assortment-based cooperation always beneficial?; how do characteristics of producers, customers, products, product profitabilities, assortments, and substitution affect the net benefit of cooperation?; how can a producer choose another producer to cooperate based on their characteristics?; if the cooperation is beneficial, is there a way of sharing the total benefit among 
the members of cooperation such that each member is better off compared to the no-cooperation case? In fact, Park and Russo (1996) point out that not all cooperations turn out to be successful ventures, and identifying keys factors for successful and sustainable cooperations lingers as an interesting research issue.

The main contribution of this paper is to develop an analytical model that can be used to explore and seek answers to such questions. We show that assortment-based cooperation is not always beneficial and the net benefit depends on the characteristics of producers, products, product profitabilities, assortment, and substitution. Once the conditions for a beneficial cooperation are set, a producer can use these conditions to select another producer to realize the potential benefit from cooperation. We propose a simple-to-implement discount-based contract scheme which enables the members of a cooperation to share the total benefit. Finally, we show that it is possible to determine the set of firms that should cooperate and set the parameters of the contract among the members of cooperation in such a way that each member of the cooperation is better off.

There is considerable amount of work on cooperation, joint ventures and network organizations in both economics and operations management. Nagarajan and Sošić (2008) and Cachon and Netessine (2004) provide comprehensive reviews of various cooperative and noncooperative game theoretic techniques for supply chains, and shed light on key concepts such as the existence and uniqueness of equilibrium in noncooperative games, as well as feasibility and stability (through bargaining and revenue sharing) in cooperative games. In our study, we assume that cooperation does not affect (at least significantly) the sizes of firms, as well as market shares and prices of the products, i.e., producers do not engage in games when establishing cooperations. This is clearly a simplification, but we believe our model can be used to understand the potential benefits of assortment-based cooperations. Since our work is mainly motivated by SMEs in the textile and apparel industry and producers in this industry do not have much power to change system dynamics significantly, this assumption is justified. Buhman et al. (2005) highlight the fact that operations management research should shift its focus from supply chain management towards 
network management so as to provide a more analytical study of such new business models and validate the potential benefits of these emerging practices. In that sense, our work is such an attempt to generate managerial insights within their framework. On the other hand, in order to identify the actual cooperation formation mechanisms yielding stable solutions, as well as the bargaining process, game theoretic models would be the natural choice. However, these issues are not central to our paper.

In the operations research literature, primary focus has been on the benefits of pooling of capacity and inventory achieved through cooperation. Benjaafar et al. (2005) study a production-inventory system with various inventory locations with each being dedicated to a particular demand stream and managed under independent base-stock policies. When the inventory is pooled, these individual demand streams are satisfied from a single location. The authors show that different system parameters including demand and process variability, service levels, and the structure of the production process, factor in determining the overall value of pooling. Meca et al. (2003) study a similar problem in the setting of an EOQ inventory system, in which a number of firms cooperate in jointly ordering their inventories, hence enjoy possible savings on fixed ordering costs. They determine the necessary and sufficient conditions under which cooperation is preferred for the individual firms. Yu et al. (2006) analyze the benefit of capacity pooling among independent firms, modelled as queuing systems in terms of serving their customers. In their model, each firm decides either to operate their own facilities or to enter a cooperation (share a facility) with another firm. Further, they optimally determine the capacity levels based on an optimization model. The authors identify the conditions so that cooperations are established and socially-optimal capacity levels are set. Tan (2006) also presents a stochastic model to analyze cooperation of producers on production capacity. An auction-based allocation method is proposed to distribute large orders and additional benefits among independent producers. In this line of research, the emphasis has been on the capacity and inventory management models proposed for the pooled inventory.

Inventory transhipment is defined as the lateral transfer of goods between warehouses, suppliers, or retailers. More specifically, a firm selling products through retailers may ask them to share 
their inventories, which enables them to decrease overall inventory levels by improving the match between supply and demand. Clearly, this procedure requires some sort of cooperation among retailers. There exists a number of papers in the literature which study transshipment of inventories among the retailers. We refer the reader to Rudi et al. (2001) and Axsaeter (2003) for reviews of recent work in this area. The two most commonly studied issues are inventory ordering, balancing and rationing implications of transhipment using stochastic models (see Diks and de Kok 1996, Ha 1997, Agrawal et al. 2004, Wee and Dada 2005, Zhao et al. 2006), and profit sharing among retailers using game theoretic approaches (see Anupindi et al. 1999 and Sošic 2006). We should mention that our paper distances itself from the inventory pooling and transhipment literature in the sense that we do not particularly consider the role of inventory in cooperation (by assuming uncapacitated firms) but include the impact of pooling and transhipment of products on the demand dimension of the problem through a consumer choice model. Assortment planning deals with determining the group of products that form the firm's assortment and setting their inventory levels based on an optimization model. Usually the optimization model maximizes the firm's total profit or sales subject to a number of constraints on budget, shelf space, etc. Kok et al. (2005) provide an extensive review of assortment planning literature and we refer the reader to their book chapter for discussions on industry practice. In our paper, we assume that each firm determines its own assortment independently and this decision is not affected by the prospect of cooperation. Hence, we are not concerned with how producers come up with their assortment decisions, but rather interested in whether cooperation would benefit them or not, given their current assortments. The details of our model will be given in Section 2 .

The remainder of this paper is organized as follows. We introduce our analytical model and basic analysis in Section 2. We explore the case where two firms in the market contemplate an assortment-based cooperation in Section 3. The case where the more than two firms cooperate are studied in Section 4. Section 5 summarizes our numerical results and Section 6 states our managerial insights derived from our analytical model. Finally, the conclusions are given in Section 7. 


\section{Analytical Model}

In this section, we introduce the basic notation and assumptions for the key dimensions of our analytical model, that we later use to derive the profit functions of a firm under two scenarios of interest; when the firm operates on its own, and when it establishes an assortment-based cooperation with another firm in the market. We use an exogenous demand model that essentially captures the behavior of consumers facing substitutable products. We also propose a discount-based contract mechanism to govern the flow of money and products among the firms participating in the cooperation.

\subsection{Problem Description}

Market. Consider a competitive market for a set of $N$ products and a set of $M$ firms, each producing a subset of these products. Let $N_{j}$, where $N_{j} \subseteq N$, be the assortment of firm $j \in M$. We assume that firms produce differentiated yet similar products. In other words, one can say that the products may be (more or less) good substitutes, but they are not perfect substitutes. Consequently, consumers have clearly defined preferences. Each consumer, identifies her first choice based on her own valuations of the products in set $N$. Let $\alpha_{i}$ be the fraction of consumers whose first choice is product $i, i \in N$, among the products available in the entire market. Let $\lambda$ be the expected number of potential buyers in the market, and $q_{j}$ be the fraction of customers who visit firm $j \in M$. Note that $q_{j}$ and $\alpha_{i}$ can be interpreted as the market shares of firm $j$ and product $i$ at the retailer and product levels, respectively. In order to distinguish between these two concepts, we refer to $q_{j}$ as the size of firm $j$ and $\alpha_{i}$ as the market share of product $i$, throughout the rest of our paper. Define $c_{i}$ as the unit variable cost of product $i, i \in N_{j}, s_{i}$ as the unit selling price of product $i$, and $p_{i}=s_{i}-c_{i}$ as the profit margin of product $i$ at firm $j$. We assume that the unit production cost (or procurement cost) of product $i$ is the same for all firms. Moreover, if multiple firms sell the same product, then the prices they charge are the same. The market structure we consider in our model can be regarded as monopolistic competition (Dixit and Stiglitz 1977). Note that the properties of monopolistic competition are about the same as perfect competition, the 
only difference being heterogeneous products, and that monopolistic competition involves a great deal of non-price competition, based on product differentiation. We should also mention that the market is at an equilibrium in steady state, meaning all problem parameters are determined after sufficient learning by firms and consumers have occurred (see Fudenberg and Levine (1993) and Kalai and Lehrer (1993) for details of reaching steady state Nash equilibrium through learning).

Demand Model. When a consumer visits a firm, she attempts to purchase her favorite product. At this point, there are two possible scenarios that might lead to substitution, as commonly considered by most assortment planning and inventory management related literature; the consumer might shift to an alternative if her first choice is produced by the firm, yet it is currently unavailable due to stockout (referred to as stockout-based substitution), or the consumer might opt for an alternative product if her first choice is not produced by the firm (referred to as assortmentbased substitution). In our problem, we focus on the latter form of substitution. Firms operate on make-to-order policy and hence no stockouts occur (alternatively one can imagine that either the make-to-stock firms maintain high service levels so that stockouts are rather rare, and consequently can be ignored, or consumers are willing to stick with their favorite products even if they are backordered). Now, suppose that, if the favorite choice of the consumer is not produced by a firm, she chooses a second favorite with probability $\theta$, or does not make a purchase and leaves the firm with probability $1-\theta$. Here, $\theta$ is a parameter characterizing the behavior of consumers. If $\theta$ is 1 , then all consumers substitute when a product is unavailable, and if $\theta$ is 0 , then none of the consumers switch to their second choices although all products are potentially substitutable. We define $\delta_{i k}$ as the probability of a consumer substituting product $i$ with product $k$. When the substitute product is also unavailable, consumers decide whether to substitute again, or alternatively not to purchase. However, a commonly made assumption in similar assortment planning models for analytical tractability is that only a single round of substitution takes place. In other words, if the second choice product is also not produced by the firm, then the consumer decides not to purchase. Smith and Agrawal (2000) and Kok and Fisher (2007) mention that the impact of limiting 
substitutions to a single round gets smaller as the variety in the product assortments gets larger, and that dynamics of multiple rounds of the substitution procedure can be approximated with a single substitution model by selecting a larger value for substitution probability $\theta$. This model of product substitution is consistent with the assumptions of utility-based logit models for consumer choice (see McFadden (1973) and Guadagni and Little (1983)).

One can express $\delta_{i k}$ in different ways in order to reflect various probabilistic substitution schemes. For example, if consumers randomly select their second favorite product then the likelihood that a consumer whose first choice is product $i$ substitutes with product $k$ can be expressed as $\delta_{i k}=\frac{\theta}{n-1}$ for $k \neq i$, where $n$ is the number of products in the market (see Smith and Agrawal (2000) and Kok et al. (2005) for a selection of these schemes). In our paper, we adopt a proportional substitution mechanism in which the rate of substitution to a product is proportional to its expected demand. Hence, we express $\delta_{i k}$ as follows

$$
\delta_{i k}=\frac{\theta \alpha_{k}}{\sum_{\ell \in N \backslash i} \alpha_{\ell}}=\frac{\theta \alpha_{k}}{1-\alpha_{i}}
$$

This demand model is not only more general than the multinomial logit (MNL) model, which is commonly used in the marketing literature, but also provides analytical tractability. Kok and Fisher (2007) provide empirical results on how these model parameters can be estimated using real life data.

Contracts. In assortment-based cooperation, cooperating firms offer the combined assortment to all of their customers. Specifically, let $C$, where $C \subseteq M$, be the set of cooperating firms. Then $N_{C}=\bigcup_{j \in C} N_{j}$ is the combined assortment of cooperating firms. In order to run the cooperation process, involving the flow of products as well as money, effectively, we assume that all firms participating in the cooperation agree on a contract, and that the contract is a discount-based mechanism. When firm $j$ does not have product $i$ in its assortment, the contract between the two cooperating firms allows firm $j$ to obtain a unit of product $i$ from firm $k$ at a cost of $\beta_{j k} s_{i}$, where $\beta_{j k}\left(0 \leq \beta_{j k} \leq 1\right)$ is a discount factor. If product $i$ is available in more than one firms in the cooperation, $\eta_{j k}^{i}$ is the fraction of the total number of units of product $i$ that firm $j$ buys from firm 
$k$. Note that if $i \in N_{j}$ then $\eta_{j k}^{i}=0$ for $k \neq j$ and $\sum_{k \in C} \eta_{j k}^{i}=1$. One can think of rather simple rules for determining $\eta_{j k}^{i}$ parameters. For example, a firm can choose to buy product $i$ from the firm which gives the larger discount, i.e., if $\beta_{j k}<\beta_{j \ell}$ then $\eta_{j k}^{i}=1$ and $\eta_{j \ell}^{i}=0$. Alternatively, a firm might be fair and buy product $i$ in equal proportions from its cooperation partners. In practice, parameters $\beta_{j k}$ and $\eta_{j k}^{i}$ are predetermined through negotiations among cooperating firms. The resulting contract also prescribes how the benefits of the cooperation are shared among its members. Cachon and Lariviere (2005) and Bernstein and Federgruen (2005) study the overall benefits of discount-based and revenue-sharing contracts (both among competing retailers as well as players within the same supply chain) and propose structural properties of these contracts that lead to market equilibrium.

\subsection{Basic Analysis}

Let us consider a particular firm $j$ with an assortment of $N_{j}$. We first compute its expected profit $\pi_{j}$ as a function of the model parameters, assuming that it does not cooperate with another firm. Let $\lambda_{i j}$ be the effective expected demand for product $i$ at firm $j$ including the substitutions to product $i$. We can express $\lambda_{i j}$ as

$$
\lambda_{i j}=\lambda q_{j}\left(\alpha_{i}+\sum_{k \notin N_{j}} \alpha_{k} \delta_{k i}\right)
$$

The first term in parenthesis in Equation (2) is the likelihood that consumers choose product $i$ because it is their favorite, and the second term is the likelihood that consumers substitute to product $i$ since their favorite is not produced by firm $j$ and product $i$ happens to be their second favorite. Therefore, the expected profit of firm $j$ is given by

$$
\begin{aligned}
\pi_{j} & =\sum_{i \in N_{j}} \lambda_{i j}\left(s_{i}-c_{i}\right) \\
& =\lambda q_{j} \sum_{i \in N_{j}}\left(\alpha_{i}+\sum_{k \notin N_{j}} \alpha_{k} \delta_{k i}\right)\left(s_{i}-c_{i}\right)
\end{aligned}
$$

In order to explain the model of assortment-based cooperation, we first consider the two-product case. Suppose that two firms, firm $j$ and firm $k$, with assortments of $N_{j}$ and $N_{k}$ respectively, decide to cooperate, i.e., $C=\{j, k\}$. Let us consider the case where a consumer whose favorite product is 
$i$ visits firm $j$. If product $i$ is produced by firm $j$, i.e., $i \in N_{j}$, firm $j$ fulfills the demand using its own inventory. However, if product $i$ is produced by firm $k$ but not by firm $j$, i.e., $i \in N_{k} \backslash N_{i}$, firm $j$ can still fulfill this demand using the inventory of firm $k$ through cooperation.

On the other hand, if product $i$ is produced by neither firm $j$ nor firm $k$, then with probability $\theta$ the consumer will substitute product $i$ with product $i^{\prime}$, her second favorite product. If product $i^{\prime}$ is produced by either firm $j$ or firm $k$, i.e., $i^{\prime} \in N_{j} \cup N_{k}$, then the consumer's demand can still be satisfied. This cooperation scheme also applies to firm $k$ symmetrically.

One can argue that cooperation would affect the sizes of the firms, as well as market shares and prices of the products, as necessitated by the new equilibrium established after cooperation. However, in this study, our main goal is to identify the structure of the substitutable products and the characteristics of firms that would benefit from cooperation, rather than examine the changes in market dynamics. Therefore, these model parameters remain the same before and after cooperation. We refer to the cooperation system proposed in our paper as the assortment-based cooperation of firms.

We can express the expected profit of firm $j$ when in cooperation with firm $k, \pi_{j}^{C}$, as follows.

$$
\pi_{j}^{C}=\sum_{i \in N_{j}} \lambda_{i j}^{C}\left(s_{i}-c_{i}\right)+\sum_{i \in N_{k} \backslash N_{j}} \lambda_{i j}^{C}\left(s_{i}-\beta_{j k} s_{i}\right)+\sum_{i \in N_{j} \backslash N_{k}} \lambda_{i k}^{C}\left(\beta_{k j} s_{i}-c_{i}\right)
$$

where $\lambda_{i j}^{C}$ is the effective expected demand for product $i$ at firm $j$ when in cooperation with firm $k$, and $\lambda_{i k}^{C}$ is the effective expected demand for product $i$ at firm $k$ when in cooperation with firm $j$. Note that the first summation in Equation (4) is the expected profit from consumers visiting firm $j$ who end up with a product produced by firm $j$. The second summation is the expected profit from consumers visiting firm $j$ who end up with a product produced by firm $k$, but not by firm $j$. Finally, the third summation is the expected profit from consumers visiting firm $k$ who end up with a product produced by firm $j$, but not by firm $k$. We have

$$
\lambda_{i j}^{C}=\lambda q_{j}\left(\alpha_{i}+\sum_{\ell \notin N_{j} \cup N_{k}} \alpha_{\ell} \delta_{\ell i}\right)
$$




$$
\lambda_{i k}^{C}=\lambda q_{k}\left(\alpha_{i}+\sum_{\ell \notin N_{j} \cup N_{k}} \alpha_{\ell} \delta_{\ell i}\right) .
$$

Substituting the above terms into Equation (4), we get

$$
\begin{aligned}
\pi_{j}^{C}= & \lambda q_{j} \sum_{i \in N_{j}}\left(s_{i}-c_{i}\right)\left(\alpha_{i}+\sum_{\ell \notin N_{j} \cup N_{k}} \alpha_{\ell} \delta_{\ell i}\right) \\
& +\lambda q_{j} \sum_{i \in N_{k} \backslash N_{j}}\left(s_{i}-\beta_{j k} s_{i}\right)\left(\alpha_{i}+\sum_{\ell \notin N_{j} \cup N_{k}} \alpha_{\ell} \delta_{\ell i}\right) \\
& +\lambda q_{k} \sum_{i \in N_{j} \backslash N_{k}}\left(\beta_{k j} s_{i}-c_{i}\right)\left(\alpha_{i}+\sum_{\ell \notin N_{j} \cup N_{k}} \alpha_{\ell} \delta_{\ell i}\right)
\end{aligned}
$$

Now let us consider the most general case where more than two firms cooperate. Then the expected profit of firm $j$ when in cooperation with firms in $C, \pi_{j}^{C}$ can be expressed as

$$
\begin{aligned}
\pi_{j}^{C}= & \lambda \sum_{i \in N_{j}} q_{j}\left(s_{i}-c_{i}\right)\left(\alpha_{i}+\sum_{\ell \notin N_{C}} \alpha_{\ell} \delta_{\ell i}\right) \\
& +\lambda \sum_{\substack{k \in C \\
k \neq j}} \sum_{i \in N_{k} \backslash N_{j}} q_{j}\left(s_{i}-\beta_{j k} s_{i}\right)\left(\alpha_{i}+\sum_{\ell \notin N_{C}} \alpha_{\ell} \delta_{\ell i}\right) \eta_{j k}^{i} \\
& +\lambda \sum_{\substack{k \in C \\
k \neq j}} \sum_{i \in N_{j} \backslash N_{k}} q_{k}\left(\beta_{k j} s_{i}-c_{i}\right)\left(\alpha_{i}+\sum_{\ell \notin N_{C}} \alpha_{\ell} \delta_{\ell i}\right) \eta_{k j}^{i}
\end{aligned}
$$

Therefore, the total profit of all the cooperating firms, $\Pi^{C}=\sum_{j \in C} \pi_{j}^{C}$, is

$$
\begin{aligned}
\Pi^{C}=\sum_{j \in C} \pi_{j}^{C}= & \lambda \sum_{j \in C} \sum_{i \in N_{j}} q_{j}\left(s_{i}-c_{i}\right)\left(\alpha_{i}+\sum_{\ell \notin N_{C}} \alpha_{\ell} \delta_{\ell i}\right) \\
& +\lambda \sum_{j \in C} \sum_{i \in N_{C} \backslash N_{j}} q_{j}\left(s_{i}-c_{i}\right)\left(\alpha_{i}+\sum_{\ell \notin N_{C}} \alpha_{\ell} \delta_{\ell i}\right) .
\end{aligned}
$$

Let the total profit of these firms before the cooperation be $\Pi=\sum_{j \in C} \pi_{j}$. We define the total change in the profit as a result of the cooperation as $\Delta \pi^{C}=\Pi^{C}-\Pi$. By using Equations (3) and (9), we can express the net change in total profit of cooperating firms as

$$
\Delta \pi^{C}=\lambda \sum_{j \in C} q_{j}\left(\sum_{i \in N_{C} \backslash N_{j}}\left(s_{i}-c_{i}\right)\left(\alpha_{i}+\sum_{\ell \notin N_{C}} \alpha_{\ell} \delta_{\ell i}\right)-\sum_{i \in N_{j}} \sum_{\ell \in N_{C} \backslash N_{j}}\left(s_{i}-c_{i}\right) \alpha_{\ell} \delta_{\ell i}\right) .
$$

Furthermore, let $\Delta \pi_{j}^{C}=\pi_{j}^{C}-\pi_{j}$ be the net change in the profit of Firm $j$ as a result of its cooperation with firms in $C$. Note that $\Delta \pi^{C}=\sum_{j \in C} \Delta \pi_{j}^{C}$. When $\Delta \pi^{C}$ is nonnegative, we refer to the cooperation as beneficial. One can show that $\Delta \pi^{C}$ can be positive or negative depending on the 
problem parameters. As Equations (9) and (10) state, the total profit after cooperation and the net change in the profit are independent of the discount factors $\beta_{j k}$ and the share fractions $\eta_{j k}, j, k \in C$. Hence, the discount factors only determine the distribution of the total profit among cooperating firms. Note that the discount-based contract mechanism allows us to focus on the assessment of overall benefits of cooperation without having to consider the impact of the contract structure on the benefits. We assume that the firms can negotiate and eventually come up with a contract for sharing the net change in the total profit effectively and efficiently.

\section{Cooperation Between Two Firms}

Consider two firms, Firm 1 and Firm 2, in a competitive market with a set of $M$ firms. Firm 1 has an assortment of $N_{1}$ whereas Firm 2 has an assortment of $N_{2}$. These two firms establish an assortment-based cooperation and offer products in $N_{1} \cup N_{2}$ to consumers. Let $\alpha_{0}$ be the likelihood that a consumer's first choice is a product not produced by either firm. We will first focus on two single-product firms and then consider a more general case with arbitrary number of products and possibly overlapping product portfolios.

\subsection{Single-Product Firms}

We first focus on the potential benefits of cooperation for two single-product firms. We define a single-product firm as a producer which produces a unique product that is differentiated from other products in the market. Suppose, Product 1 is produced by Firm 1 and Product 2 by Firm 2, i.e., $N_{1}=\{1\}$ and $N_{2}=\{2\}$. The likelihood that a consumer prefers a product other than either Product 1 or Product 2 (an outside option we refer to as Product 0 ) is $\alpha_{0}=1-\alpha_{1}-\alpha_{2}$. Using Equation (10), the net change in total profit after these two producers cooperate can be written as be follows

$$
\begin{aligned}
\Delta \pi^{C}= & \lambda \alpha_{1} p_{1}\left\{q_{2}\left(1+\frac{\theta \alpha_{0}}{1-\alpha_{0}}\right)-q_{1} \frac{\theta \alpha_{2}}{1-\alpha_{2}}\right\} \\
& +\lambda \alpha_{2} p_{2}\left\{q_{1}\left(1+\frac{\theta \alpha_{0}}{1-\alpha_{0}}\right)-q_{2} \frac{\theta \alpha_{1}}{1-\alpha_{1}}\right\} .
\end{aligned}
$$

When $\Delta \pi^{C}$ is nonnegative, we refer to the cooperation as beneficial. In order to gain further insights on the conditions under which an assortment-based cooperation is beneficial, we focus on three key 
parameters of our problem, the sizes of the the two firms $\left(q_{1}, q_{2}\right)$, market shares of products in their assortments $\left(\alpha_{1}, \alpha_{2}\right)$, and their profitabilities $\left(p_{1}, p_{2}\right)$. As suggested earlier, depending on these system parameters, $\Delta \pi^{C}$ can be positive or negative. However, based on Proposition 5 , we already know that these two producers would definitely benefit from cooperation if they are symmetric firms. Hence, a recommendation for producers is to form networks with those that are similar in their sizes, product market shares, and profit margins. Nevertheless, it might also be possible for a firm to benefit from cooperation with another producer that is not similar in model parameters. In order to determine the characteristics of such a producer, we now consider cases with asymmetric producers.

First, let us consider the case where the market shares of Product 1 and Product 2 are the same, $\left(\alpha_{1}=\alpha_{2}\right)$. The following proposition states the conditions for the profit margins of the two products so that cooperation is beneficial for the firms.

Proposition 1 Cooperation is beneficial for two asymmetric single-product firms with identical product market shares, when

1. the product of the smaller firm is more profitable than that of the larger firm, i.e., $\left(p_{1}>p_{2}\right.$, $\left.q_{1}<q_{2}\right)$ or $\left(p_{1}<p_{2}, q_{1}>q_{2}\right)$,

2. the product of the larger firm is more profitable than that of the smaller firm and a thresholdtype criteria is satisfied, i.e., $\left(p_{1}>p_{2}, q_{1}>q_{2}\right)$ or $\left(p_{1}<p_{2}, q_{1}<q_{2}\right)$, and $\left(p_{1}-p_{2}\right)\left(q_{1}-q_{2}\right)$ is less than a certain threshold.

The proof is given in Appendix B.1.

Proposition 1 basically states that when the market shares of the products are the same, a smaller producer with a more profitable product is a suitable partner to cooperate for a particular firm. Despite its limited size and ability to generate substantial additional traffic for the larger firm, each additional sale of its product generates a larger profit and therefore creates added benefit for cooperation. Otherwise, if a producer is larger than its counterpart in the cooperation and also produces the more profitable product, cooperation may be detrimental. This is due to potential 
profit loss created by the stream of substitutions from the more profitable product to the less profitable product after cooperation.

Next, suppose that Firm 1 and Firm 2 have the same size, $\left(q_{1}=q_{2}\right)$. The following proposition states the conditions for the profit margins of the two products so that cooperation is beneficial for these firms.

Proposition 2 Cooperation is beneficial for two asymmetric single-product firms with identical sizes, when

1. the product with the larger market share is also more profitable than the product with the smaller market share, i.e., $\left(p_{1}>p_{2}, \alpha_{1}>\alpha_{2}\right)$ or $\left(p_{1}<p_{2}, \alpha_{1}<\alpha_{2}\right)$, or

2. the product with the larger market share is less profitable than the product with the smaller market share, and a threshold-type criteria is satisfied, i.e., $\left(p_{1}>p_{2}, \alpha_{1}<\alpha_{2}\right)$ or $\left(p_{1}<p_{2}, \alpha_{1}>\alpha_{2}\right)$ and $\left(p_{1}-p_{2}\right)\left(\alpha_{1}-\alpha_{2}\right)$ is less than a certain threshold.

The proof is given in Appendix B.2.

Proposition 2 states that when the firm sizes are the same, a firm that has a product with a larger market share and a higher profit margin is a suitable partner to cooperate for a particular firm. All orders that are substituted to a lower profit product or lost at the other firm before cooperation are turned into profit for the cooperation. Otherwise, cooperation with a firm that produces a product with a larger market share but with a lower profit margin can be disadvantageous due to losing the profit from substitution to the higher profit product.

Finally, suppose the products that each firm produces have the same profit margins, $p_{1}=p_{2}$. The next proposition states the conditions for the sizes of these firms so that cooperation is beneficial for them.

Proposition 3 Cooperation is beneficial for two asymmetric single-product firms with identical profit margins for their products, when 
1. the firm that produces the product with a larger market share is smaller than the firm that produces the product with a smaller market share, i.e., $\left(q_{1}<q_{2}, \alpha_{1}>\alpha_{2}\right)$ or $\left(q_{1}>q_{2}, \alpha_{1}<\alpha_{2}\right)$, or

2. the firm that produces the product with a larger market share is larger than the firm that produces the product with a smaller market share, and a threshold-criteria is satisfied, i.e., $\left(q_{1}<q_{2}\right.$, $\left.\alpha_{1}<\alpha_{2}\right)$ or $\left(q_{1}>q_{2}, \alpha_{1}>\alpha_{2}\right)$, and $\left(q_{1}-q_{2}\right)\left(\alpha_{1}-\alpha_{2}\right)$ is less than a certain threshold.

The proof is given in Appendix B.3.

When the profit margins are the same, choosing a suitable partner depends on the additional traffic the cooperation generates that is otherwise lost. If a firm is larger than its counterpart and also produces a product with a higher market share, cooperation with a smaller firm that produces a product with a smaller market share may cannibalize the orders that are otherwise substituted to its own product. Otherwise, cooperation between a smaller firm that produces a product with a higher market share and a larger firm that produces a product with a lower market share allows them to benefit from the stronger characteristics of the other firm. As a result, cooperation allows them to enjoy an opportunity in the market that neither of the firms can exploit on its own, which we can refer to as the emergence of synergy in the market.

\subsection{Firms with Overlapping Product Assortments}

Now we focus on firms with possibly overlapping product assortments, i.e. the set $N_{1} \cap N_{2}$ may not be empty. Based on Equation (10), we can write the change in total profits of these two firms after cooperation as follows

$$
\begin{aligned}
\Delta \pi^{C}= & \lambda q_{1}\left\{\sum_{i \in N_{2} \backslash N_{1}} p_{i}\left(\alpha_{i}+\alpha_{0} \delta_{0 i}\right)-\sum_{i \in N_{1}} \sum_{\ell \in N_{2} \backslash N_{1}} p_{i} \alpha_{\ell} \delta_{\ell i}\right\} \\
& +\lambda q_{2}\left\{\sum_{i \in N_{1} \backslash N_{2}} p_{i}\left(\alpha_{i}+\alpha_{0} \delta_{0 i}\right)-\sum_{i \in N_{2}} \sum_{\ell \in N_{1} \backslash N_{2}} p_{i} \alpha_{\ell} \delta_{\ell i}\right\}
\end{aligned}
$$

which can also be written as

$$
\Delta \pi^{C}=\lambda q_{1}\left\{\sum_{i \in N_{2} \backslash N_{1}} p_{i}\left(\alpha_{i}+\alpha_{0} \delta_{0 i}\right)-\left(\sum_{i \in N_{1} \backslash N_{2}} \sum_{\ell \in N_{2} \backslash N_{1}} p_{i} \alpha_{\ell} \delta_{\ell i}+\sum_{i \in N_{1} \cap N_{2}} \sum_{\ell \in N_{2} \backslash N_{1}} p_{i} \alpha_{\ell} \delta_{\ell i}\right)\right\}
$$




$$
+\lambda q_{2}\left\{\sum_{i \in N_{1} \backslash N_{2}} p_{i}\left(\alpha_{i}+\alpha_{0} \delta_{0 i}\right)-\left(\sum_{i \in N_{2} \backslash N_{1}} \sum_{\ell \in N_{1} \backslash N_{2}} p_{i} \alpha_{\ell} \delta_{\ell i}+\sum_{i \in N_{1} \cap N_{2}} \sum_{\ell \in N_{1} \backslash N_{2}} p_{i} \alpha_{\ell} \delta_{\ell i}\right)\right\}
$$

Rearranging the terms of the above expression and substituting $\delta_{i k}=\frac{\theta \alpha_{k}}{1-\alpha_{i}}$, we get

$$
\begin{aligned}
\Delta \pi^{C}= & \sum_{i \in N_{2} \backslash N_{1}} \lambda \alpha_{i} p_{i}\left[q_{1}\left(1+\frac{\theta \alpha_{0}}{1-\alpha_{0}}\right)-\sum_{\ell \in N_{1} \backslash N_{2}} q_{2} \frac{\theta \alpha_{\ell}}{1-\alpha_{\ell}}\right] \\
& +\sum_{i \in N_{1} \backslash N_{2}} \lambda \alpha_{i} p_{i}\left[q_{2}\left(1+\frac{\theta \alpha_{0}}{1-\alpha_{0}}\right)-\sum_{\ell \in N_{2} \backslash N_{1}} q_{1} \frac{\theta \alpha_{\ell}}{1-\alpha_{\ell}}\right] \\
& -\sum_{i \in N_{1} \cap N_{2}} \lambda \alpha_{i} p_{i}\left[\sum_{\ell \in N_{2} \backslash N_{1}} q_{1} \frac{\theta \alpha_{\ell}}{1-\alpha_{\ell}}+\sum_{\ell \in N_{1} \backslash N_{2}} q_{2} \frac{\theta \alpha_{\ell}}{1-\alpha_{\ell}}\right]
\end{aligned}
$$

Proposition 4 Adding the same products to the product assortments of two firms adversely affects the net change in total profits after cooperation.

Proof. Based on Equation (12), the change in total profits of firms after cooperation, $\Delta \pi^{C}$, decreases if the number of products common to both firms increases as a result of adding the same products to the product assortment of two firms, i.e., the set $N_{1} \cap N_{2}$ gets larger while the sets $N_{1} \backslash N_{2}$ and $N_{2} \backslash N_{1}$ stay the same. Moreover, as the profitability and market share of a product shared by the two firms increase, $\Delta \pi^{C}$ once again decreases. Note that although $\Delta \pi^{C}$ decreases as the set $N_{1} \cap N_{2}$ gets larger, adding a product to the product assortment of a firm may increase its own profit.

Proposition 5 Assortment-based cooperation is always beneficial for any two firms with symmetric sizes, product market shares, product profit margins, and the same number of products.

Proof. Suppose that $q_{1}=q_{2}=q$, and $\alpha_{i}=\alpha, p_{i}=p$ for $i \in N_{1} \cup N_{2}$. Let $\left|N_{1}\right|=\left|N_{2}\right|=n$ and $\varphi$ be the fraction of the number of products in $N_{1} \cap N_{2}$, i.e., $\left|N_{1} \cap N_{2}\right|=\varphi n$. Then Equation (12) can be written as

$$
\Delta \pi^{C}=2 \lambda \alpha p q n \alpha(1-\varphi)\left[1+\frac{\theta \alpha_{0}}{1-\alpha_{0}}-\frac{n \theta \alpha}{1-\alpha}\right]
$$


Since $\left|N_{1} \cup N_{2}\right|=n(2-\varphi), \alpha_{0}=1-n(2-\varphi)$. Substituting this identity into the above expression yields $\Delta \pi^{C}=2 \lambda \alpha p q n(1-\varphi) \Phi(\alpha)$ where

$$
\Phi(\alpha)=\alpha+\frac{\theta(1-\alpha n(2-\varphi))}{n(2-\varphi)}-\frac{n \theta \alpha^{2}}{1-\alpha} .
$$

When $\alpha=0, \Phi(0)=\frac{\theta}{n(2-\varphi)} \geq 0$. Since $0 \leq \alpha_{0} \leq 1, \alpha \leq \frac{1}{n(2-\varphi)}$. When $\alpha=\frac{1}{n(2-\varphi)}, \Phi\left(\frac{1}{n(2-\varphi)}\right)=$ $1-\frac{\theta n}{2 n-1-\varphi n}$. Since $\varphi n \geq 1$ and integer, $\theta \leq 1$, and $n \geq 2, \Phi\left(\frac{1}{n(2-\varphi)}\right) \geq 0$. It can also be shown that $\ddot{\Phi}(\alpha)=-\frac{2 \theta n}{(1-\alpha)^{3}}<0$ and therefore $\Phi(\alpha)$ is a concave function. As a result $\Phi(\alpha)$ is always nonnegative for all permissable values of system parameters. Hence $\Delta \pi^{C} \geq 0$, meaning assortment-based cooperation is always beneficial for two symmetric firms, producers with identical key parameters, no matter much how their products overlap with each other.

Proposition 6 The benefit of assortment-based cooperation decreases as the number of overlapping products increases for any two firms with symmetric sizes, product market shares, product profit margins, and the same number of products.

Proof. Taking the derivative of $\Delta \pi^{C}$ given in Equation (13) with respect to $\varphi$ yields

$$
\frac{d}{d \varphi} \Delta \pi^{C}=2 \lambda \alpha p q n\left[-\alpha(1-\theta)-\frac{\theta}{(2-\varphi)^{2}}+\frac{n \theta \alpha^{2}}{1-\alpha}\right]
$$

By using $\varphi n \geq 1, \theta \leq 1, n \geq 2$, and $\alpha \leq \frac{1}{n(1-\varphi)}$, it is shown that the above expression is always negative for all permissible values of $\varphi$ that makes $n \varphi$ an integer. Therefore $\Delta \pi^{C}$ decreases as the number of overlapping products increases for two symmetric firms with identical key parameters.

Now suppose that an assortment-based cooperation is potentially beneficial for two firms, i.e., $\Delta \pi^{C} \geq 0$. How the extra total profit generated with cooperation is distributed among cooperating firms is an important factor for decision makers in determining whether or not to join the cooperation. In other words, if the surplus generated from the cooperation is not shared fairly between the producers, neither of them will be willing to participate in the cooperation. Rather than prescribing a fair allocation mechanism, we will show that a discount-based contract scheme, an allocation that 
makes the net change in each firm's profit after cooperation nonnegative, exists in the business model we propose. Note that, according to Equation (12), the net change in the total profit after cooperation is independent of the discount factors $\beta_{12}$ and $\beta_{21}$. Hence, the discount factors only determine the distribution of the total profit between Firm 1 and Firm 2.

Proposition 7 When an assortment-based cooperation is beneficial for two firms, i.e., $\Delta \pi^{C}=$ $\Delta \pi_{1}^{C}+\Delta \pi_{2}^{C} \geq 0$, one can always find two discount factors $0 \leq \beta_{12} \leq 1$ and $0 \leq \beta_{21} \leq 1$ such that $\Delta \pi_{1}^{C} \geq 0$ and $\Delta \pi_{2}^{C} \geq 0$.

The proof is given in the Appendix.

Proposition 7 shows that the surplus can be shared efficiently between the producers by adjusting the discounts each firm gives to its counterpart. We leave the determination of these discount factors to the negotiation process of the firms. Intuitively a firm that wants to cooperate with a stronger firm applies a high discount rate to this firm and accepts even a low discount rate. However, one would expect that similar firms or firms with characteristics that complement each other apply similar discount factors. Note that if one wants to prescribe a specific allocation mechanism, any of the mechanisms developed in cooperative game theory can be used. Alternatively, we propose a mathematical programming model which maximizes the overall benefit of firms in an assortment-based cooperation to determine the optimal discount factors, as well as the structure of the cooperation, in Section 4.2. The proposed model determines the discount factors not only for two firms but for a more general setting, as will be explained in later sections.

\section{Cooperation Among Multiple (More than Two) Firms}

In the most general problem setting, the market consists of a set of $M$ firms and a set of $N$ products, some of which might be produced by more than one firm. Suppose a group of firms, denoted by set $C$, where $C \subseteq M$, establish a network organization in the form of an assortment-based cooperation. We derived the expression for the net change in the total profit of the firms, taking part in this cooperation, denoted by $\Delta \pi^{C}$, in Section 2.2 , as 


$$
\Delta \pi^{C}=\lambda \sum_{j \in C} q_{j}\left(\sum_{i \in N_{C} \backslash N_{j}} p_{i}\left(\alpha_{i}+\sum_{\ell \notin N_{C}} \alpha_{\ell} \delta_{\ell i}\right)-\sum_{i \in N_{j}} \sum_{\ell \in N_{C} \backslash N_{j}} p_{i} \alpha_{\ell} \delta_{\ell i}\right)
$$

Note that the above expression is a function of $\alpha_{i}$ and $p_{i}$ for $i \in N$, and $q_{j}$ for $j \in C$. Since the number of problem parameters is prohibitively large to study their individual impact on the benefit from cooperation analytically, as we did in Section 3, we conduct a simulation-based numerical study to generate insights. The results of this study will be given in Section 5 . Therefore, in this section we focus on the cooperation among multiple symmetric single-product firms. We present our analytical results on the benefits of cooperation for these firms as well as some structural properties of the resulting cooperation.

\subsection{Symmetric Single-Product Firms}

In Proposition 5, we stated that assortment-based cooperation between two multi-product firms with possibly overlapping product assortments and symmetric product market shares, firm sizes and profit margins, is always beneficial. The following proposition extends this result to multiple symmetric single-product firms. In other words, if any number of single-product firms with symmetric parameters decide to cooperate, they will each benefit from this venture.

Proposition 8 Assortment-based cooperation is always beneficial for symmetric single-product firms.

The proof is given in Appendix C.1

Moreover, the marginal benefit of each additional firm joining the cooperation is non-negative, which not only means that the net change in total profit (benefit of assortment-based cooperation) increases as more and more firms join the cooperation, but also the benefit enjoyed by each firm increases with each extra firm. The next proposition states that this observation would dictate that a cooperation involving all members of the market would be the most beneficial among all possible cooperations.

Proposition 9 In a market with $|M|=m$ symmetric single-product firms, it is always beneficial to add one more member to an existing cooperation. Hence, a cooperation which involves all $m$ 
firms (grand coalition) yields larger profit to each firm compared to other forms of cooperation (sub-coalitions).

The proof is given in Appendix C.2.

\subsection{A Mathematical Programming Approach to Coalition Forming}

In this paper, we assume that cooperations among firms is established through discount-based contracts. Proposition 7 in Section 3.2 states that one can always find feasible discount factors for two firms such that cooperation is beneficial for each firm when the net change in total profit is non-negative for a given cooperation. However, when firms choose partners for cooperation, how to determine the optimal discount factors, as well as the whom to cooperate with for the optimal benefit are not trivial questions. Moreover, for the general problem setting, with nonsymmetric firms, determining the structure of the best cooperation scheme, i.e., finding whether a single cooperation involving all firms in the market (grand coalition) or multiple cooperations with subsets of the firms in the market are formed, is a rather challenging task, unlike the case with symmetric single-product firms. Note that, the structure of the ensuing cooperations also depends on the cooperation forming mechanism imposed on the firms.

For the general problem with $|M|$ firms, we propose a practical mathematical programming model, given in (14)-(22), to determine the general cooperation structure in the market that potentially might include multiple cooperations to maximize the total benefit of all the firms while maintaining that each firm is better off compared to all the other alternative potential cooperations. Therefore, the optimal solution is also an equilibrium. The decision variables of the optimization model are the assignments of each firm to one of the possible cooperations and the discount rates between each firm couple. Let $K$ be the set of all possible cooperations, including the case where no cooperations form, as illustrated in the above example. More specifically, $I_{j, k}$ is a binary variable indicating to whether firm $j$ is participating in cooperation $k \in K, \beta_{i, j}$ is the discount rate given to firm $i$ by

firm $j, C_{k}$ is the set of firms in cooperation $k$, and $v_{j}^{C_{k}}$ is the profit of firm $j$ if it participates in cooperation $k$. The math program sets the discount rates and decides on the assignments of 
firms to cooperations simultaneously. The objective function is given by the total profit of firms as a result of formed cooperations. Therefore, this approach can be interpreted as a cooperative mechanism, as referred to in game theory, that also maximizes the total welfare in the market. The constraints in the model ensure that cooperations are formed without any conflicts, i.e., each firm is assigned to one cooperation and all firms in a cooperation cannot be assigned to another cooperation (by assumption). Furthermore, the optimal assignment is the preferred one for all the firms and they cannot increase their own benefit through other cooperations and discount factor values. The math program is as follows

$$
\begin{aligned}
& \max \sum_{j \in M} \sum_{k \in K} v_{j}^{C_{k}} \\
& \text { s.t. } \\
& \sum_{k \in K} I_{j, k}=1, \quad \forall j \in M \\
& I_{j, k}=I_{j^{\prime}, k}, \quad \text { if } j \in C_{k} \text { and } j^{\prime} \in C_{k}, \forall j, j^{\prime} \in M \\
& \pi_{j}^{C_{k}}-\pi_{j}^{C_{k^{\prime}} \geq} \geq-\mathcal{Q}\left(1-I_{j, k}\right), \quad k \neq k^{\prime}, \forall j \in M \text { and } \forall k, k^{\prime} \in K \\
& \pi_{j}^{C_{k}} \geq v_{j}^{C_{k}}, \quad \forall j \in M \text { and } \forall k \in K \\
& \mathcal{Q} I_{j, k} \geq v_{j}^{C_{k}}, \quad \forall j \in M \text { and } \forall k \in K \\
& I_{j, k} \in\{0,1\}, \forall j \in M \text { and } \forall k \in K \\
& v_{j}^{C_{k}} \geq 0, \quad \forall j \in M \text { and } \forall k \in K \\
& 1 \geq \beta_{j, j^{\prime}} \geq 0, \quad \forall j, j^{\prime} \in M, j \neq j^{\prime}
\end{aligned}
$$

In the above formulation, $\mathcal{Q}$ is a sufficiently large positive number. Further, if there are $|M|=m$ firms in the market, the number of possible cooperations with at least two firms is $2^{m}-m-1$. Including the case, in which no cooperations occur, the number of assignment variables turns out to be $2^{m}-m$ and the number of discount rate decision variables is $\frac{m(m-1)}{2}$. Also note that $\pi_{j}^{C_{k}}$ values, which are calculated using Equation (4), are linear functions of the discount rates $\beta_{j, j^{\prime}}$. Hence, the above program is a mixed integer linear program. 
The objective function given in Equation (14) maximizes the total profit as a result of the cooperation structure. Equation (15) forces each firm to be assigned to one of the $k$ possible cooperations (note that $k=1$ means no cooperations take place). Equation (16) implies that if firm $j$ is in cooperation $k$, which involves another firm $j^{\prime}$, that particular firm $j^{\prime}$ should be actually assigned to cooperation $k$. Inequalities (18) ensures that the profit of firm $j$ in cooperation $k$ is bounded by $\pi_{j}^{C_{k}}$ which is computed using Equation (4). Note that the actual profit of firm $j$ when participating in cooperation $k$ is only computed if firm $j$ is assigned to cooperation $k$ due to inequality (19). Finally, inequality in (17) states that if a firm is assigned to a particular cooperation, its profit from this cooperation is no worse than what it would have made from all the other possible cooperation assignments. We should mention that the discount factors, $\beta_{j k}$, can have multiple optimal values due to the fact that the total profit of firms participating in the cooperation is independent of the discount values.

In order to illustrate various optimal cooperation scenarios suggested by the above mathematical program given in (14)-(22), we consider the following examples with three firms $(1,2$ and 3 ) and three products $(\mathcal{A}, \mathcal{B}$ and $\mathcal{C})$. Firm 1 produces $\mathcal{A}$ and $\mathcal{B}$, Firm 2 produces $\mathcal{B}$ and $\mathcal{C}$, and Firm 3 produces $\mathcal{C}$. In this market, there are five possible cooperation scenarios that include nocooperation, cooperation consisting of only two firms, and cooperation of all firms (grand coalition), as shown in the table below.

\begin{tabular}{ccl}
$k$ & $C_{k}$ & Cooperation Structure \\
\hline 1 & \{\} & No cooperations form \\
2 & $\{1,2\}$ & Firm 1 and Firm 2 cooperate \\
3 & $\{1,3\}$ & Firm 1 and Firm 3 cooperate \\
4 & $\{2,3\}$ & Firm 2 and Firm 3 cooperate \\
5 & $\{1,2,3\}$ & All firms cooperate (grand coalition) \\
\hline
\end{tabular}

In all examples, we assume $\lambda=100$ and $\theta=0.8$. For notational simplicity let $\alpha=\left(\alpha_{\mathcal{A}}, \alpha_{\mathcal{B}}, \alpha_{\mathcal{C}}\right)$, $\mathbf{p}=\left(p_{\mathcal{A}}, p_{\mathcal{B}}, p_{\mathcal{C}}\right)$ and $\mathbf{q}=\left(q_{1}, q_{2}, q_{3}\right)$. Now consider the following problem instances.

Case 1 Suppose $\alpha=(0.1,0.1,0.1), \mathbf{p}=(1,1,1)$, and $\mathbf{q}=(0.1,0.1,0.1)$. With these particular parameters values, the optimal strategy for all firms is to form a grand coalition. The discount factors can be selected as $50 \%$ except for $\beta_{31}=100 \%$. 
Case 2 Suppose $\alpha=(0.2,0.3,0.5), \mathbf{p}=(3,2,1)$, and $\mathbf{q}=(0.8,0.1,0.1)$. Using these set of parameters, Firm 2 and Firm 3 form a cooperation with $\beta_{32}=23.3 \%$. Note that since Firm 3 does not produce any product that is not in the assortment of Firm $2, \beta_{23}$ is not used and Firm 1 remains outside. Note also that Firm 1 is the largest of the three firms and also produces the most profitable product, namely $\mathcal{A}$. Hence, it is suboptimal for Firm 1 to share its profits with the other two. The following table illustrates the net profit of each firm (with optimal discount factors) under five different cooperation possibilities. We can see that profit values with $C_{k}=\{2,3\}$ dominate all solutions under other cooperation schemes. Therefore, this solution is also an equilibrium.

\begin{tabular}{ccrrr}
$k$ & $C_{k}$ & $\pi_{1}^{C_{k}}$ & $\pi_{2}^{C_{k}}$ & $\pi_{3}^{C_{k}}$ \\
\hline 1 & \{\} & 172.80 & 9.60 & 7.71 \\
2 & $\{1,2\}$ & 142.00 & 11.00 & 7.71 \\
3 & $\{1,3\}$ & 141.48 & 9.60 & 11.52 \\
4 & $\{2,3\}$ & $\mathbf{1 7 2 . 8 0}$ & $\mathbf{1 1 . 0 0}$ & $\mathbf{1 1 . 5 2}$ \\
5 & $\{1,2,3\}$ & 138.10 & 17.00 & 14.90
\end{tabular}

Case 3 Suppose $\alpha=(0.1,0.6,0.2), \mathbf{p}=(2,1,3)$, and $\mathbf{q}=(0.1,0.2,0.3)$. In this case, no cooperations are formed and all firms are better off when they act on their own.

\section{Computational Results}

In order to get an overall insight on the benefits of assortment-based cooperation among firms in a competitive market, we run simulations for a wide range of problem settings. In our simulations, each problem instance corresponds to a random set of values (or ranges of values) for certain key problem parameters that can influence the final results. For a given market of $|M|$ firms and $|N|$ products, we randomly generate the market shares and profit margins of the products, the sizes of the firms as well as the substitution probability of consumers. We assume that the number of products in the assortment of each firm is the same for a particular scenario. However, the assortment of a firm is determined as a random subset of the products available in the market. In fact the ratio $\frac{\left|N_{j}\right|}{|N|}$, assuming values between 0 and 1 , can be interpreted as a product coverage index. As the value of this index increases, one can understand that a firm produces a wider range of products compared to all available products in the market. Furthermore, a random subset of firms 
in the market are assumed to participate in an assortment-based cooperation (we assume only one cooperation exists in the market). In each scenario, the number of firms in cooperation is fixed. We introduce the cooperation coverage index, $\frac{|C|}{|M|}$, indicating how large the formed cooperation is with respect to the entire market. Namely, a cooperation coverage index of 0 means no cooperations are formed, whereas an index of 1 states that a grand coalition exists. These two indices allow us to make comparisons between different market structures, governed by the relative values of the number of products and number of firms in the market.

Table 1 Normalized Average Percentage Benefits for Assortment-Based Cooperation

\begin{tabular}{|c|c|c|c|c|c|c|c|c|c|c|c|c|}
\hline \multirow[b]{2}{*}{$|M|$} & \multirow[b]{2}{*}{$|N|$} & \multirow[b]{2}{*}{$\frac{|C|}{|M|}$} & \multicolumn{10}{|c|}{$\left|N_{j}\right| /|N|$} \\
\hline & & & 0.1 & 0.2 & 0.3 & 0.4 & 0.5 & 0.6 & 0.7 & 0.8 & 0.9 & 1.0 \\
\hline \multirow[t]{9}{*}{10} & 10 & 0.2 & 0.202 & 0.143 & 0.111 & 0.085 & 0.065 & 0.048 & 0.033 & 0.020 & 0.009 & 0.000 \\
\hline & & 0.3 & 0.327 & 0.236 & 0.170 & 0.125 & 0.089 & 0.062 & 0.040 & 0.023 & 0.010 & 0.000 \\
\hline & & 0.4 & 0.437 & 0.293 & 0.205 & 0.144 & 0.100 & 0.066 & 0.042 & 0.023 & 0.010 & 0.000 \\
\hline & & 0.5 & 0.518 & 0.337 & 0.227 & 0.154 & 0.103 & 0.068 & 0.042 & 0.023 & 0.010 & 0.000 \\
\hline & & 0.6 & 0.593 & 0.369 & 0.239 & 0.159 & 0.106 & 0.068 & 0.043 & 0.023 & 0.010 & 0.000 \\
\hline & & 0.7 & 0.666 & 0.390 & 0.248 & 0.161 & 0.106 & 0.068 & 0.042 & 0.023 & 0.010 & 0.000 \\
\hline & & 0.8 & 0.714 & 0.411 & 0.256 & 0.164 & 0.107 & 0.068 & 0.042 & 0.023 & 0.010 & 0.000 \\
\hline & & 0.9 & 0.763 & 0.420 & 0.258 & 0.165 & 0.106 & 0.068 & 0.041 & 0.023 & 0.010 & 0.000 \\
\hline & & 1.0 & 0.802 & 0.431 & 0.259 & 0.165 & 0.106 & 0.068 & 0.042 & 0.023 & 0.010 & 0.000 \\
\hline \multirow[t]{9}{*}{10} & 20 & 0.2 & 0.169 & 0.132 & 0.106 & 0.084 & 0.064 & 0.047 & 0.033 & 0.020 & 0.009 & 0.000 \\
\hline & & 0.3 & 0.298 & 0.220 & 0.165 & 0.123 & 0.089 & 0.062 & 0.040 & 0.023 & 0.010 & 0.000 \\
\hline & & 0.4 & 0.407 & 0.283 & 0.202 & 0.143 & 0.099 & 0.067 & 0.042 & 0.024 & 0.010 & 0.000 \\
\hline & & 0.5 & 0.493 & 0.330 & 0.224 & 0.152 & 0.104 & 0.069 & 0.043 & 0.024 & 0.010 & 0.000 \\
\hline & & 0.6 & 0.573 & 0.361 & 0.237 & 0.159 & 0.106 & 0.069 & 0.043 & 0.024 & 0.010 & 0.000 \\
\hline & & 0.7 & 0.637 & 0.388 & 0.248 & 0.163 & 0.108 & 0.069 & 0.043 & 0.024 & 0.010 & 0.000 \\
\hline & & 0.8 & 0.693 & 0.405 & 0.254 & 0.165 & 0.108 & 0.070 & 0.043 & 0.024 & 0.010 & 0.000 \\
\hline & & 0.9 & 0.740 & 0.420 & 0.256 & 0.165 & 0.108 & 0.069 & 0.043 & 0.024 & 0.010 & 0.000 \\
\hline & & 1.0 & 0.784 & 0.429 & 0.260 & 0.165 & 0.108 & 0.069 & 0.043 & 0.024 & 0.010 & 0.000 \\
\hline \multirow[t]{9}{*}{20} & 10 & 0.2 & 0.437 & 0.292 & 0.205 & 0.144 & 0.099 & 0.066 & 0.042 & 0.024 & 0.010 & 0.000 \\
\hline & & 0.3 & 0.599 & 0.369 & 0.239 & 0.161 & 0.107 & 0.068 & 0.042 & 0.023 & 0.010 & 0.000 \\
\hline & & 0.4 & 0.717 & 0.409 & 0.255 & 0.163 & 0.106 & 0.068 & 0.042 & 0.023 & 0.010 & 0.000 \\
\hline & & 0.5 & 0.804 & 0.434 & 0.260 & 0.164 & 0.107 & 0.068 & 0.041 & 0.023 & 0.010 & 0.000 \\
\hline & & 0.6 & 0.868 & 0.444 & 0.262 & 0.165 & 0.106 & 0.067 & 0.042 & 0.023 & 0.009 & 0.000 \\
\hline & & 0.7 & 0.912 & 0.454 & 0.264 & 0.163 & 0.106 & 0.068 & 0.042 & 0.023 & 0.010 & 0.000 \\
\hline & & 0.8 & 0.952 & 0.458 & 0.264 & 0.163 & 0.105 & 0.066 & 0.041 & 0.023 & 0.010 & 0.000 \\
\hline & & 0.9 & 0.980 & 0.461 & 0.262 & 0.163 & 0.105 & 0.067 & 0.041 & 0.023 & 0.010 & 0.000 \\
\hline & & 1.0 & 1.000 & 0.460 & 0.261 & 0.163 & 0.105 & 0.067 & 0.042 & 0.023 & 0.010 & 0.000 \\
\hline
\end{tabular}

Let us illustrate how we generate a random problem instance for a particular scenario. Note that a scenario is defined by the number of firms and products in the market, as well as the number 
of products in the assortment of firms and the number of firms participating in cooperation. For example, $|M|=20,|N|=10,|C|=4$, and $\left|N_{j}\right|=3$ describes a scenario with 20 firms and 10 products, where each firm produces 3 products for its assortment, and cooperations are formed with 4 firms. A random problem instance for this scenario is generated by each of the 20 firms randomly selecting 3 products from the set of 10 products, and a random group of 4 firms forming a cooperation. The profit margin for each of the 10 products are drawn from uniform distributions between 0 and 1 . Further, the sizes of the 20 firms are first drawn from a uniform distribution between 0 and 1, and then normalized so that the sum of the firm sizes is equal to 1 . The market shares of the 10 products are generated in the same manner. Finally the substitution probability of consumers, $\theta$, is also drawn from a uniform distribution between 0 and 1 . With all these values, we compute the net change in total profit of the firms participating in cooperation using Equation (10). Assuming that potential gains and losses are shared equally among cooperating firms, we determine the percent benefit for each firm. In our simulation study, for every scenario, we generate 10000 such random problem instances. Table 1 reports the average of the percent benefit per firm in the cooperation, for 270 different problem scenarios, normalizing with respect to the best scenario outcome (a 20 firm 10 product market in which firms have only one product and form a grand coalition). Normalization is done so that we can make meaningful comparisons between different scenarios to generate insights on the relative benefit of assortment-based cooperation.

Table 1 is composed of three panels. In the first panel, we give our simulation results for a market in which the number of products and firms are balanced. The second panel presents results for a market where few firms select their potential assortments from a large number of products. Finally the last panel reports results for a market with a larger number of firms producing a limited variety of products. Our numerical results in all of the three panels indicate that the benefit from assortment-based cooperation increases as the cooperation size, measured in terms of the cooperation coverage index $\frac{|C|}{|M|}$, increases. Figure 1 displays this observation for a 10 firm - 10 product market structure at different levels of the product coverage index. Note that, the marginal benefit from cooperation decreases with each new addition to a cooperation, illustrated 


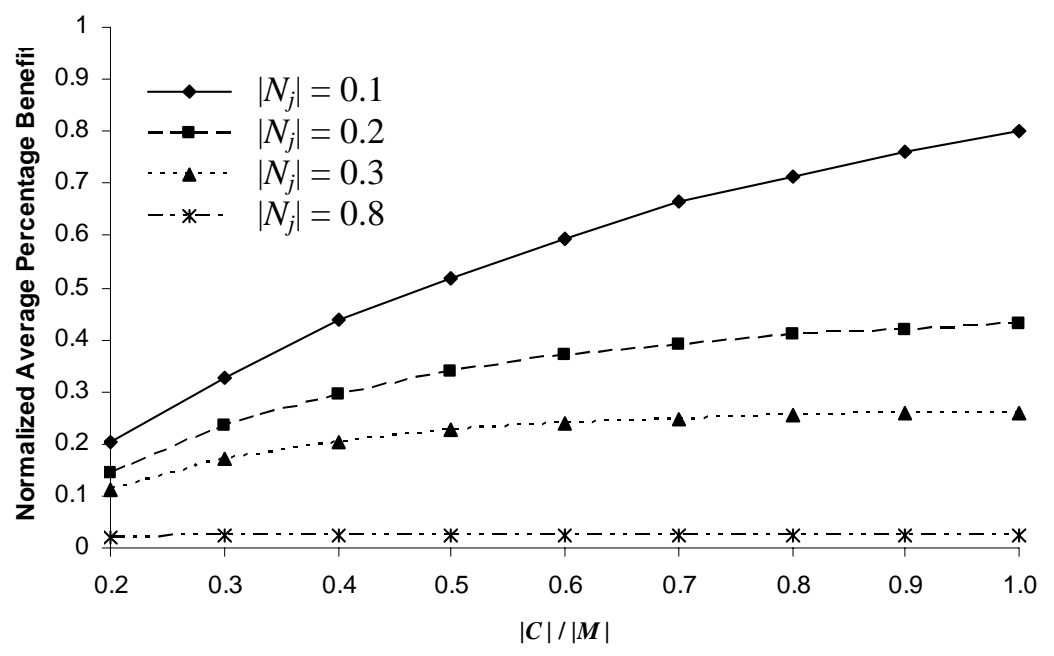

Figure 1 Normalized Average Percentage Benefits for $|M|=10$ and $|N|=10$

by the concave increasing functions in the figure. We also observe that the benefit from cooperation decreases significantly as the number of products in the firm assortments increases. The main reason for this is the fact that, as the value of product coverage index, $\frac{\left|N_{j}\right|}{|N|}$ increases, the likelihood that firms in the cooperation have overlapping product assortments increases. As shown in Proposition 4, this has a negative effect on the benefit from cooperation.

Figure 2 displays the normalized average percentage benefits for markets with different number of firms and products, as a function of the product coverage index, $\frac{\left|N_{j}\right|}{|N|}$. In all the cases in the figure, cooperations cover $30 \%$ of the entire market (similar patterns are observed at different levels of the cooperation coverage index, $\left.\frac{|C|}{|M|}\right)$. As noted earlier, the benefit from cooperation decreases as the likelihood of common product assortments increases. However, we also note that, assortment-based cooperation is more beneficial for markets with a larger number of firms. This can also be verified by comparing the three panels in Table 1.

\section{Managerial Insights}

Although our analytical model is simple, it is rather helpful in generating interesting managerial insights for the decision makers. Using our results, we can conjecture on the circumstances under which an assortment-based cooperation established among independent producers yields beneficial outcomes. At this point, we should remind the reader that, we treat the size of a producer (in 


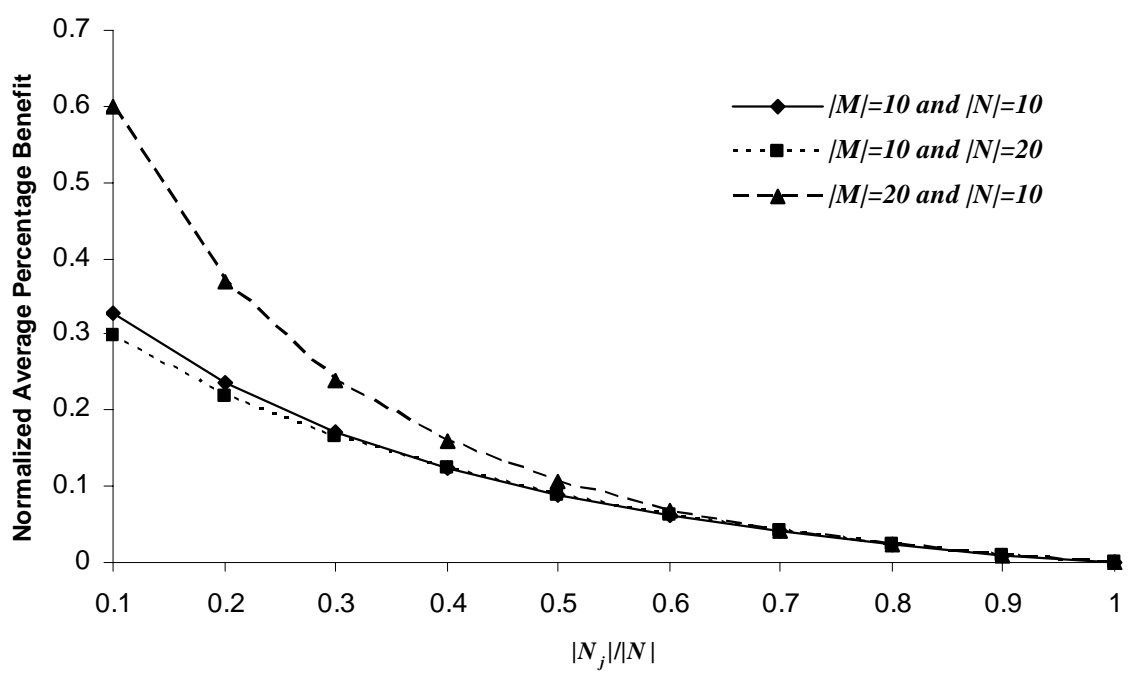

Figure 2 Normalized Average Percentage Benefits for $\frac{|C|}{|M|}=0.3$

terms of the percentage of consumers who visit the producer), market shares of its products and profitabilities from these products as the key leverages determining the overall success of cooperation.

Let us consider a decision maker at a single-product firm who is contemplating an assortmentbased cooperation opportunity with another single-product firm. Propositions 1, 2, and 3 set the conditions for a beneficial cooperation. Accordingly, depending on the ordering of firms sizes, market shares and product profitabilities, either the cooperation is always beneficial or an additional threshold-type condition needs to be satisfied to have a beneficial cooperation. Hence, an assortment- based cooperation is not always beneficial, as one might initially assume that it would be, unless the ensuing synergy is justified.

Table 2 summarizes these suggested actions for a decision maker.

Based on our results, we list the summary findings that provide managerial insights on cooperation strategies, as follows:

1. For the cooperation to succeed, each partner should contribute either with its size or with its more profitable product. If a producer dominates another firm with both its size and also with the profitability of its product, cooperation between these producers can decrease the overall total profit. 
Table 2 Summary of results for choosing a partner for single-product firms

\begin{tabular}{|c|c|c|c|c|}
\hline \multicolumn{2}{|c|}{$\begin{array}{c}\text { Identical } \\
\text { Profit Margins }\end{array}$} & \multicolumn{3}{|c|}{$\begin{array}{c}\text { market share of } \\
\text { potential partner's product }\end{array}$} \\
\hline & & smaller & equal & larger \\
\hline \multirow{3}{*}{$\begin{array}{c}\text { size of } \\
\text { potential } \\
\text { partner }\end{array}$} & smaller & THRESHOLD & ALWAYS & ALWAYS \\
\hline & equal & ALWAYS & ALWAYS & ALWAYS \\
\hline & larger & ALWAYS & ALWAYS & THRESHOLD \\
\hline
\end{tabular}

\begin{tabular}{|c|c|c|c|c|}
\hline \multirow{2}{*}{\multicolumn{2}{|c|}{$\begin{array}{l}\text { Identical } \\
\text { Firm Sizes }\end{array}$}} & \multicolumn{3}{|c|}{$\begin{array}{c}\text { market share of } \\
\text { potential partner's product }\end{array}$} \\
\hline & & smaller & equal & larger \\
\hline \multirow{3}{*}{$\begin{array}{c}\text { profit margin } \\
\text { of potential } \\
\text { partner's product }\end{array}$} & smaller & ALWAYS & ALWAYS & THRESHOLD \\
\hline & equal & ALWAYS & ALWAYS & ALWAYS \\
\hline & larger & THRESHOLD & ALWAYS & ALWAYS \\
\hline
\end{tabular}

\begin{tabular}{|c|c|c|c|c|}
\hline \multirow{2}{*}{\multicolumn{2}{|c|}{$\begin{array}{c}\text { Identical } \\
\text { Market Shares }\end{array}$}} & \multicolumn{3}{|c|}{$\begin{array}{c}\text { size of } \\
\text { potential partner }\end{array}$} \\
\hline & & smaller & equal & larger \\
\hline \multirow{3}{*}{$\begin{array}{c}\text { profit margin } \\
\text { of potential } \\
\text { partner's product }\end{array}$} & smaller & THRESHOLD & ALWAYS & ALWAYS \\
\hline & equal & ALWAYS & ALWAYS & ALWAYS \\
\hline & larger & ALWAYS & ALWAYS & THRESHOLD \\
\hline
\end{tabular}

AlWAYs: Assortment-based cooperation is always beneficial

ThresholD: Unless a threshold-type criteria is satisfied, the assortment-based cooperation is not beneficial

2. Adding a product with a higher market share and a higher profit margin to an assortment that already includes a product with a lower market share and a lower profit margin increases the total profit of cooperating firms. On the other hand, cooperation of a producer with a more profitable niche product and producer with a less profitable product with a higher market share might be detrimental for the producers.

3. If a producer is larger than its counterpart in the cooperation and also produces a product with a higher market share, cooperation with the smaller firm that produces a product with a smaller market share may cannibalize the demand for its own demand traffic.

4. When firms form network organizations, they should choose partners that would extend their product assortments. When two firms share common products in their assortments, the overall benefit from cooperation is adversely affected.

5. When firms profit from the demand substituted to a common product, cooperation with a firm that produces a product that has a lower profit margin reduces its profit. Therefore, cooperation of two similar firms will be beneficial when the profitability of the common product 
is lower than the specialized products.

6. The marginal benefit from assortment-based cooperation decreases as the firms assortments include larger portions of products in the market, as well as the cooperations include fewer participating firms, as illustrated by our numerical studies. Cooperation is more beneficial in markets with larger number of competing firms.

\section{Conclusions}

In this study, we model and analyze assortment-based cooperation as a potentially beneficial business model for improving competitiveness of firms with limited resources. The analytical model developed for assortment-based cooperation captures the impact of key dimensions of the problem, namely, product characteristics (their market shares and profit margins), substitution among these products, firm sizes, and firm assortments, on the results of a possible cooperation among these firms.

In this setting, we analytically show that symmetric single-product firms always benefit from cooperation. On the other hand, when the firms are not symmetric, cooperation can have negative effects on the overall profit. We also show that for assortment-based cooperation to be beneficial for all parties involved, certain threshold-type criteria should be satisfied on a number of the problem parameters. Intuitively, these conditions imply that the cooperation of firms with complementary characteristics is beneficial.

After showing that the assortment-based cooperation is an effective business model when the right firms cooperate, we also suggest a discount-based contract that can be easily used. Rather that prescribing a fair allocation mechanism, we show that these discount factors can be adjusted to allocate the total surplus such a way that the net increase in each firm's profit is non-negative. We propose a mathematical programming formulation to determine the optimal values of the discount factors, and identify the cooperations to be formed in a market, which maximizes the overall benefit of the market from cooperation.

In order to investigate the benefits of cooperation in a more comprehensive way, a general model that incorporates capacity, inventory, and assortment dimensions of the problem can also 
be developed. Furthermore, our model of cooperation does not include costs related to cooperation forming, such as administrative costs, transhipment costs, etc. We leave these extensions as future research direction.

\section{Acknowledgments}

The authors would like to thank the Editor, Departmental Editor, and reviewers for their valuable comments and suggestions which have considerably improved the paper.

\section{References}

Agrawal, V., X. Chao, S. Seshadri. 2004. Dynamic balancing of inventory in supply chains. European Journal of Operational Research 159(2) 296-317.

Anupindi, R., Y. Bassok, E. Zemel. 1999. Study of decentralized distribution systems: Part 2. Working paper, Northwestern University.

Axsaeter, S. 2003. A New Decision Rule for Lateral Transshipments in Inventory Systems. Management Science 49(9) 1168-1179.

Benjaafar, S., W. L. Cooper, J.S. Kim. 2005. On the benefits of pooling in production-inventory systems. Management Science 51(4) 548-565.

Bernstein, F., A. Federgruen. 2005. Decentralized Supply Chains with Competing Retailers Under Demand Uncertainty. Management Science 51(1) 18-29.

Buhman, C., S. Kekre, J. Singhal. 2005. Interdisciplinary and interorganizational research: Establishing the science of enterprise networks. Production and Operations Management 14(4) 493-513.

Cachon, G., S. Netessine. 2004. Handbook of Quantitative Supply Chain Analysis: Modeling in the eBusiness Era, chap. Game theory in Supply Chain Analysis. Kluwer.

Cachon, G.P., M.A. Lariviere. 2005. Supply Chain Coordination with Revenue-Sharing Contracts: Strengths and Limitations. Management Science 51(1) 30-44.

Diks, EB, AG de Kok. 1996. Controlling a divergent 2-echelon network with transshipments using the consistent appropriate share rationing policy. International Journal of Production Economics 45369 379. 
Dixit, A.K., J.E. Stiglitz. 1977. Monopolistic Competition and Optimum Product Diversity. The American Economic Review 67(3) 297-308.

Ergun, Ö., G. Kuyzu, M. Savelsbergh. 2007. Shipper collaboration. Computers and Operations Research 34(6) 1551-1560.

Fudenberg, D., D.K. Levine. 1993. Steady State Learning and Nash Equilibrium. Econometrica 61(3) $547-573$.

Ghemawat, P., C.F. Foley. 1998. Cooperating to compete: EGS of Turkey. Case study, Harvard Business School. Reference No. 9-799-024.

Guadagni, P.M., J.D.C. Little. 1983. A logit model of brand choice calibrated on scanner data. Marketing Science 2(3) 203-238.

Ha, A.Y. 1997. Inventory Rationing in a Make-to-Stock Production System with Several Demand Classes and Lost Sales. Management Science 43(8) 1093-1103.

Johnston, R., P.R. Lawrence. 1988. Beyond vertical integration - the rise of the value-adding partnership. Harvard Business Review 66(4) 94-101.

Kalai, E., E. Lehrer. 1993. Rational Learning Leads to Nash Equilibrium. Econometrica 61(5) 1019-1045.

Kok, A. G., M. L. Fisher. 2007. Demand Estimation and Assortment Optimization Under Substitution: Methodology and Application. Operations Research 55(6) 1001-1021.

Kok, A.G., M.L. Fisher, R. Vaidyanathan. 2005. Assortment Planning: Review of Literature and Industry Practice. Retail Supply Chain Management. Kluwer, Amsterdam .

Kumar, K., H. G. van Dissel, P. Bielle. 1996. The merchant of Prato - revisited: Towards a third rationality of information systems. Management Information Systems Quarterly 1-37.

Lin, M. H. 2004. Strategic airline alliances and endogenous stackelberg equilibria. Transportation Research Part E 40 357-384.

McFadden, D. 1973. Conditional Logit Analysis of Qualitative Choice Behavior. Institute of Urban and Regional Development, University of California.

Meca, A., I. García-Jurado, P. Borm. 2003. Cooperation and competition in inventory games. Mathematical Methods of Operations Research 57(3) 481-493. 
Mezgár, I., G. Kovács, P. Paganelli. 2000. Co-operative production planning for small- and medium-sized enterprises. International Journal of Production Economics 64 37-48.

Nagarajan, M., G. Sošić. 2008. Game-theoretic analysis of cooperation among supply chain agents: Review and extensions. European Journal of Operational Research 187(3) 719-745.

Park, J. H. 1997. The effects of airline alliances on markets and economic welfare. Transportation Research Part E 33(3) 181-195.

Park, S. H., M. V. Russo. 1996. When competition eclipses cooperation: An event history analysis of joint venture failures. Management Science 42(6) 875-890.

Rudi, N., S. Kapur, D.F. Pyke. 2001. A Two-Location Inventory Model with Transshipment and Local Decision Making. Management Science 47(12) 1668-1680.

Smith, S.A., N. Agrawal. 2000. Management of Multi-Item Retail Inventory Systems with Demand Substitution. Operations Research 48(1) 50-64.

Sošic, G. 2006. Transshipment of Inventories Among Retailers: Myopic vs. Farsighted Stability. Management Science 52(10) 1493-1508.

Sulzer, A. 2001. The business of cooperation: Peace and profit through joint ventures. Harvard International Review 23(2) 34-36.

Tan, B. 2006. Modeling and analysis of a network organizations for cooperation of producers on production capacity. Mathematical Problems in Engineering 2006 1-24. Article ID 85103.

Van Alstyne, M. 1997. The state of network organization: A survey in three frameworks. Journal of Organizational Computing and Electronic Commerce 7 83-151.

Wee, K.E., M. Dada. 2005. Optimal Policies for Transshipping Inventory in a Retail Network. Management Science 51(10) 1519-1533.

Yu, Y., S. Benjaafar, Y. Gerchak. 2006. On service capacity pooling and cost sharing among independent firms. Working paper, University of Minnesota.

Zhao, H., V. Deshpande, J.K. Ryan. 2006. Emergency Transshipment in Decentralized Dealer Networks: When to Send and Accept Transshipment Requests. Naval Research Logistics 53.

\section{Appendix. Proofs of Statements}




\section{A. Proof of Proposition 7}

From Equation (3), we can write the profit functions of Firm 1 and Firm 2, before cooperations, as follows

$$
\begin{aligned}
& \pi_{1}=\lambda q_{1} \sum_{i \in N_{1}}\left(\alpha_{i}+\sum_{k \notin N_{1}} \alpha_{k} \delta_{k i}\right)\left(s_{i}-c_{i}\right) \\
& \pi_{2}=\lambda q_{2} \sum_{i \in N_{2}}\left(\alpha_{i}+\sum_{k \notin N_{2}} \alpha_{k} \delta_{k i}\right)\left(s_{i}-c_{i}\right)
\end{aligned}
$$

The profit of Firm 1, after cooperation is given by

$$
\begin{aligned}
\pi_{1}^{\{1,2\}}= & \lambda q_{1} \sum_{i \in N_{1}}\left(s_{i}-c_{i}\right)\left(\alpha_{i}+\sum_{\ell \notin N_{1} \cup N_{2}} \alpha_{\ell} \delta_{\ell i}\right)+\lambda q_{1} \sum_{i \in N_{2} \backslash N_{1}}\left(s_{i}-\beta_{12} s_{i}\right)\left(\alpha_{i}+\sum_{\ell \notin N_{1} \cup N_{2}} \alpha_{\ell} \delta_{\ell i}\right) \\
& +\lambda q_{2} \sum_{i \in N_{1} \backslash N_{2}}\left(\beta_{21} s_{i}-c_{i}\right)\left(\alpha_{i}+\sum_{\ell \notin N_{1} \cup N_{2}} \alpha_{\ell} \delta_{\ell i}\right)
\end{aligned}
$$

which can also be written as

$$
\begin{aligned}
\Delta \pi_{1}^{\{1,2\}}= & -\lambda q_{1} \sum_{i \in N_{1}} \sum_{\ell \in N_{2} \backslash N_{1}}\left(s_{i}-c_{i}\right) \alpha_{\ell} \delta_{\ell i}+\lambda q_{1} \sum_{i \in N_{2} \backslash N_{1}} s_{i}\left(\alpha_{i}+\sum_{\ell \notin N_{1} \cup N_{2}} \alpha_{\ell} \delta_{\ell i}\right)-\lambda q_{2} \sum_{i \in N_{1} \backslash N_{2}} c_{i}\left(\alpha_{i}+\sum_{\ell \notin N_{1} \cup N_{2}} \alpha_{\ell} \delta_{\ell i}\right) \\
& -\beta_{12} \lambda q_{1} \sum_{i \in N_{2} \backslash N_{1}} s_{i}\left(\alpha_{i}+\sum_{\ell \notin N_{1} \cup N_{2}} \alpha_{\ell} \delta_{\ell i}\right)+\beta_{21} \lambda q_{2} \sum_{i \in N_{1} \backslash N_{2}} s_{i}\left(\alpha_{i}+\sum_{\ell \notin N_{1} \cup N_{2}} \alpha_{\ell} \delta_{\ell i}\right)
\end{aligned}
$$

Similarly, using Equation (7), we can write the profit of Firm 2 after cooperation as

$$
\begin{aligned}
\Delta \pi_{2}^{\{1,2\}}= & -\lambda q_{2} \sum_{i \in N_{2}} \sum_{\ell \in N_{1} \backslash N_{2}}\left(s_{i}-c_{i}\right) \alpha_{\ell} \delta_{\ell i}+\lambda q_{2} \sum_{i \in N_{1} \backslash N_{2}} s_{i}\left(\alpha_{i}+\sum_{\ell \notin N_{1} \cup N_{2}} \alpha_{\ell} \delta_{\ell i}\right)-\lambda q_{1} \sum_{i \in N_{2} \backslash N_{1}} c_{i}\left(\alpha_{i}+\sum_{\ell \notin N_{1} \cup N_{2}} \alpha_{\ell} \delta_{\ell i}\right) \\
& -\beta_{21} \lambda q_{2} \sum_{i \in N_{1} \backslash N_{2}} s_{i}\left(\alpha_{i}+\sum_{\ell \notin N_{1} \cup N_{2}} \alpha_{\ell} \delta_{\ell i}\right)+\beta_{12} \lambda q_{1} \sum_{i \in N_{2} \backslash N_{1}} s_{i}\left(\alpha_{i}+\sum_{\ell \notin N_{1} \cup N_{2}} \alpha_{\ell} \delta_{\ell i}\right)
\end{aligned}
$$

Then the net change in total profits of these two firms is given by

$$
\begin{aligned}
\Delta \pi^{C}= & \Delta \pi_{1}^{\{1,2\}}+\Delta \pi_{2}^{\{1,2\}} \\
= & \lambda q_{1}\left\{\sum_{i \in N_{2} \backslash N_{1}}\left(s_{i}-c_{i}\right)\left(\alpha_{i}+\alpha_{0} \delta_{0 i}\right)-\sum_{i \in N_{1}} \sum_{\ell \in N_{2} \backslash N_{1}}\left(s_{i}-c_{i}\right) \alpha_{\ell} \delta_{\ell i}\right\} \\
& +\lambda q_{2}\left\{\sum_{i \in N_{1} \backslash N_{2}}\left(s_{i}-c_{i}\right)\left(\alpha_{i}+\alpha_{0} \delta_{0 i}\right)-\sum_{i \in N_{2}} \sum_{\ell \in N_{1} \backslash N_{2}}\left(s_{i}-c_{i}\right) \alpha_{\ell} \delta_{\ell i}\right\}
\end{aligned}
$$

Now, suppose $\Delta \pi_{1}^{\{1,2\}}+\Delta \pi_{2}^{\{1,2\}} \geq 0$ and also define the following parameters

$$
\begin{gathered}
A_{1}=-\lambda q_{1} \sum_{i \in N_{1}} \sum_{\ell \in N_{2} \backslash N_{1}}\left(s_{i}-c_{i}\right) \alpha_{\ell} \delta_{\ell i}+\lambda q_{1} \sum_{i \in N_{2} \backslash N_{1}} s_{i}\left(\alpha_{i}+\sum_{\ell \notin N_{1} \cup N_{2}} \alpha_{\ell} \delta_{\ell i}\right)-\lambda q_{2} \sum_{i \in N_{1} \backslash N_{2}} c_{i}\left(\alpha_{i}+\sum_{\ell \notin N_{1} \cup N_{2}} \alpha_{\ell} \delta_{\ell i}\right) \\
A_{2}=-\lambda q_{2} \sum_{i \in N_{2}} \sum_{\ell \in N_{1} \backslash N_{2}}\left(s_{i}-c_{i}\right) \alpha_{\ell} \delta_{\ell i}+\lambda q_{2} \sum_{i \in N_{1} \backslash N_{2}} s_{i}\left(\alpha_{i}+\sum_{\ell \notin N_{1} \cup N_{2}} \alpha_{\ell} \delta_{\ell i}\right)-\lambda q_{1} \sum_{i \in N_{2} \backslash N_{1}} c_{i}\left(\alpha_{i}+\sum_{\ell \notin N_{1} \cup N_{2}} \alpha_{\ell} \delta_{\ell i}\right) \\
B=\lambda q_{2} \sum_{i \in N_{1} \backslash N_{2}} s_{i}\left(\alpha_{i}+\sum_{\ell \notin N_{1} \cup N_{2}} \alpha_{\ell} \delta_{\ell i}\right)
\end{gathered}
$$




$$
C=\lambda q_{1} \sum_{i \in N_{2} \backslash N_{1}} s_{i}\left(\alpha_{i}+\sum_{\ell \notin N_{1} \cup N_{2}} \alpha_{\ell} \delta_{\ell i}\right)
$$

Using these definitions, we can write $\Delta \pi_{1}^{C}$ and $\Delta \pi_{1}^{C}$ as

$$
\begin{aligned}
& \Delta \pi_{1}^{C}=A_{1}+B \beta_{21}-C \beta_{12} \\
& \Delta \pi_{2}^{C}=A_{2}-B \beta_{21}+C \beta_{12}
\end{aligned}
$$

Now let us consider the set of inequalities

$$
\begin{aligned}
A_{1}+B \beta_{21}-C \beta_{12} & \geq 0 \\
A_{2}-B \beta_{21}+C \beta_{12} & \geq 0 \\
1 \geq \beta_{21} & \geq 0 \\
1 \geq \beta_{12} & \geq 0 .
\end{aligned}
$$

This set of inequalities has a feasible solution if and only if $-\frac{A_{2}}{C} \leq 1$ and $-\frac{A_{1}}{B} \leq 1$. Comparing the terms of $A_{1}+B$ and $A_{1}+A_{2}$ yields that, since $\Delta \pi^{C}=A_{1}+A_{2} \geq 0, A_{1}+B \geq 0$ and therefore $-\frac{A_{1}}{B} \leq 1$. Similarly, Comparing the terms of $A_{2}+C$ and $A_{1}+A_{2}$ yields $-\frac{A_{2}}{C} \leq 1$. As a result, the set of inequalities above has always a feasible solution and therefore one can always find discount factors $0 \leq \beta_{12} \leq 1$ and $0 \leq \beta_{21} \leq 1$ such that $\Delta \pi_{1}^{C} \geq 0$ and $\Delta \pi_{2}^{C} \geq 0$.

\section{B. Proofs of Propositions in Section 3.1}

Preliminary. When $q_{1}=q_{2}=q, \alpha_{1}=\alpha_{2}=\alpha$, and $p_{1}=p_{2}=p$, Equation (11) can be written as

$$
\Delta \pi^{C}=\lambda q p\left(\frac{2 \alpha^{2}+\alpha(3 \theta-2)-\theta}{\alpha-1}\right)
$$

Let $\Phi(\alpha)=\frac{2 \alpha^{2}+\alpha(3 \theta-2)-\theta}{\alpha-1}$. Since $\frac{\partial^{2} \Phi}{\partial \alpha^{2}}=\frac{4 \theta}{(\alpha-1)^{3}} \leq 0$ for all possible values of $\alpha$ and $\theta, \Phi(\alpha)$ is concave in $\alpha$. Further $\Phi(0)=\theta \geq 0$ and $\Phi\left(\frac{1}{2}\right)=1-\theta \geq 0$. Hence, $\Phi(\alpha)$ is nonnegative. As a result, the net change in total profit, $\Delta \pi^{C}$ in equation (23), is also nonnegative.

\section{B.1. Proof of Proposition 1}

In this case, we assume that $\alpha_{1}=\alpha_{2}=\alpha$. Define $q_{1}=q+\Delta q$ and $q_{2}=q-\Delta q$, and let $p_{1}=p+\Delta p$ and $p_{2}=p-\Delta p$. Then the net change in total profit given in Equation (11) can be written as 


$$
\Delta \pi^{C}=\lambda p q \frac{2 \alpha^{2}+\alpha(3 \theta-2)-\theta}{(\alpha-1)}-\lambda \Delta p \Delta q \frac{2 \alpha^{2}(2 \theta-1)+\alpha(2-3 \theta)+\theta}{(1-\alpha)}
$$

For $\Delta \pi^{C}$ to be nonnegative, the following inequality should hold

$$
\Delta p \Delta q \leq \frac{p q\left(-2 \alpha^{2}+\alpha(2-3 \theta)+\theta\right)}{2(2 \theta-1) \alpha^{2}+\alpha(2-3 \theta)+\theta}
$$

Since $-2 \alpha^{2}-\alpha(3 \theta-2)+\theta \geq 0$ for all $\alpha \in\left[0, \frac{1}{2}\right]$ and all $\theta \in[0,1]$, and $-2 \alpha^{2}-\alpha(3 \theta-2)+\theta \leq$ $2(2 \theta-1) \alpha^{2}+\alpha(2-3 \theta)+\theta$, the right hand side of inequality $(25)$ is always in the interval $[0,1]$. Note that when $\Delta p=0$, i.e., $p_{1}=p_{2}$, or when $\Delta q=0$, i.e., $q_{1}=q_{2}$, the term $\Delta p \Delta q$ is 0 . Therefore the inequality is satisfied and the cooperation is beneficial. Similarly when $\Delta p \Delta q<0$, i.e., when $\left(p_{1}>p_{2}, q_{1}<q_{2}\right)$ or when $\left(p_{1}<p_{2}, q_{1}>q_{2}\right)$, inequality (25) is satisfied. Otherwise, when $\Delta p \Delta q>0$, i.e., when $\left(p_{1}>p_{2}, q_{1}>q_{2}\right)$ or when $\left(p_{1}<p_{2}, q_{1}<q_{2}\right)$ the term $\Delta p \Delta q$ should not exceed the threshold on the right hand side of (25) so that cooperation benefits the two firms.

\section{B.2. Proof of Proposition 2}

Let $\alpha_{1}=\alpha+\Delta \alpha, \alpha_{2}=\alpha-\Delta \alpha, p_{1}=p+\Delta p$, and $p_{2}=p-\Delta p$. Then, using equation (11), the net change in the total profit can be written as

$$
\begin{aligned}
\Delta \pi^{C}= & \lambda p q \frac{2 \alpha\left((1-\alpha)^{2}-\Delta \alpha^{2}\right)+\theta\left((1-3 \alpha)(1-\alpha)+\Delta \alpha^{2}\right)}{(1-\alpha)^{2}-\Delta \alpha^{2}} \\
& +2 \Delta p \Delta \alpha q \lambda\left(1+\frac{\theta(1-2 \alpha)}{2 \alpha}+\frac{\left(\alpha^{2}-\Delta \alpha^{2}\right) \theta}{(1-\alpha)^{2}-\Delta \alpha^{2}}\right)
\end{aligned}
$$

Notice that the first term of the summation in equation (26) is the same as the right hand side of equation (23) when $\Delta \alpha=0$. In the preliminary, we showed that this term is nonnegative. Since $\alpha \geq \Delta \alpha$ and $1-\alpha \geq \Delta \alpha$, first term of the summation in the above expression is also nonnegative. Moreover, since $\alpha \leq \frac{1}{2}$,

$$
\frac{\theta(1-2 \alpha)}{2 \alpha}+\frac{\left(\alpha^{2}-\Delta \alpha^{2}\right) \theta}{(1-\alpha)^{2}-\Delta \alpha^{2}} \geq 0
$$

Therefore, the second term of the summation in equation (26) is also nonnegative if $\Delta p \Delta \alpha \geq 0$. On the other hand, $\Delta \pi^{C}$ will still be nonnegative, for $\Delta p \Delta \alpha<0$, if $\Delta p \Delta \alpha$ satisfies the following criteria.

$$
\Delta p \Delta \alpha \leq \frac{-2 \alpha^{2} p\left((1-\alpha)^{2}-\Delta \alpha^{2}\right)+2 \theta \alpha\left((1-3 \alpha)(1-\alpha)+\Delta \alpha^{2}\right)}{2 \alpha\left[(1-\alpha)^{2}-\Delta \alpha^{2}\right]+\theta(1-2 \alpha)\left[(1-\alpha)^{2}-\Delta \alpha^{2}\right]+2 \theta \alpha\left(\alpha^{2}-\Delta \alpha^{2}\right)}
$$




\section{B.3. Proof of Proposition 3}

Let $\alpha_{1}=\alpha+\Delta \alpha, \alpha_{2}=\alpha-\Delta \alpha, q_{1}=q+\Delta q$, and $q_{2}=q-\Delta q$. Then the net change in the total profit can be written as

$$
\begin{aligned}
\Delta \pi^{C}= & \lambda p q \frac{2 \alpha\left((1-\alpha)^{2}-\Delta \alpha^{2}\right)+\theta\left((1-3 \alpha)(1-\alpha)+\Delta \alpha^{2}\right)}{(1-\alpha)^{2}-\Delta \alpha^{2}} \\
& -2 \Delta q \Delta \alpha p \lambda\left(1+\frac{\theta(1-2 \alpha)}{2 \alpha}+\frac{\left(\alpha^{2}-\Delta \alpha^{2}\right) \theta}{(1-\alpha)^{2}-\Delta \alpha^{2}}\right)
\end{aligned}
$$

Following our proof of Proposition 2 and using the similarity of equation (26) and equation (28), notice that $\Delta \pi^{C}$ is nonnegative when $\Delta q \Delta \alpha \leq 0$ or when $\Delta q \Delta \alpha>0$ and

$$
\Delta q \Delta \alpha \leq \frac{2 q \alpha^{2}\left((1-\alpha)^{2}-\Delta \alpha^{2}\right)+2 \theta \alpha\left((1-3 \alpha)(1-\alpha)+\Delta \alpha^{2}\right)}{2 \alpha\left[(1-\alpha)^{2}-\Delta \alpha^{2}\right]+\theta(1-2 \alpha)\left[(1-\alpha)^{2}-\Delta \alpha^{2}\right]+2 \theta \alpha\left(\alpha^{2}-\Delta \alpha^{2}\right)}
$$

\section{Proofs of Propositions in Section 4}

\section{C.1. Proof of Proposition 8}

We consider $m$ symmetrical single-product firms. Let $\alpha_{0}=1-\sum_{i=1}^{m} \alpha_{i}$ be the market share of products that are not produced by these $m$ firms, representing the outside option. The net change in total profit of these $m$ firms after cooperation can be written by using Equation (10) as

$$
\Delta \pi^{C}=\sum_{i=1}^{m} \sum_{j=1, j \neq i}^{m} \lambda p_{i} q_{j}\left(\alpha_{i}+\alpha_{0} \frac{\theta \alpha_{i}}{1-\alpha_{0}}\right)-\sum_{i=1}^{m} \sum_{j=1, j \neq i}^{m} \lambda p_{i} q_{i}\left(\alpha_{j} \frac{\theta \alpha_{i}}{1-\alpha_{j}}\right)
$$

Let $\alpha_{i}=\alpha=\frac{1-\alpha_{0}}{m}, q_{i}=q$, and $p_{i}=p$, for $i=1, \ldots, m$. The above equation then reduces to

$$
\Delta \pi^{C}=\lambda p q m(m-1)\left(\alpha+\frac{\alpha_{0} \theta \alpha}{1-\alpha_{0}}-\frac{\theta \alpha^{2}}{1-\alpha}\right) .
$$

Substituting $\alpha_{0}=1-m \alpha$ into Equation (31) yields

$$
\Delta \pi^{C}=\lambda p q(m-1) \frac{\alpha^{2} m+\alpha((m+1) \theta-m)-\theta}{(\alpha-1)}
$$

When $\alpha=0, \Delta \pi^{C}=\lambda p q(m-1) \theta>0$. Similarly when $\alpha=\frac{1}{m}, \Delta \pi^{C}=\lambda p q(m-1-\theta)>0 . \Delta \pi^{C}$ reaches its unique maximum of $\lambda \operatorname{pqm}(m-1)\left((1-\sqrt{\theta})^{2}+\theta\right)>0$ at $\alpha^{*}=1-\sqrt{\theta}$. Therefore $\Delta \pi^{C} \geq 0$ for all $0 \leq \alpha \leq \frac{1}{m}$. 


\section{C.2. Proof of Proposition 9}

Since there are $|M|=m$ single-product firms and $|M|=m$ products, we set $\alpha=\frac{1}{m}$ and $q=\frac{1}{m}$. In this market, let us consider an existing cooperation of $k$ firms, where $k<m$. All the products that are not produced by this cooperation are lumped into a single product with $\alpha_{0}=1-k \alpha=\frac{m-k}{m}$ as the outside option. The net change in total profit can be written by using Equation (10) as

$$
\Delta \pi^{C_{k}}=\lambda p q k(k-1)\left(\alpha+\frac{\alpha_{0} \theta \alpha}{1-\alpha_{0}}-\frac{\theta \alpha^{2}}{1-\alpha}\right) .
$$

Since the firms are symmetric, the total benefit is naturally shared equally among $k$ firms. Substituting $\alpha=\frac{1}{m}, q=\frac{1}{m}$, and $\alpha_{0}=\frac{m-k}{m}$ into the above equation yields the net change in the profit of Firm $i$, where $i \in C_{k}$, can be computed as

$$
\Delta \pi_{i}^{C_{k}}=\lambda p \frac{k-1}{m^{2}}\left(1+\frac{\theta(m-k)}{k}-\frac{\theta}{m-1}\right) .
$$

Now let us consider the case of adding one more member to this cooperation. In this case, the net increase in Firm $i$ 's profit can be written directly from Equation (35) by replacing $k$ with $k+1$ that yields

$$
\Delta \pi_{i}^{C_{k+1}}=\lambda p \frac{k}{m^{2}}\left(1+\frac{\theta(m-k-1)}{k+1}-\frac{\theta}{m-1}\right) .
$$

$\pi_{i}^{C_{k+1}}-\pi_{i}^{C_{k}}$ can be derived from Equations (35) and (34) as

$$
\Delta \pi_{i}^{C_{k+1}}-\Delta \pi_{i}^{C_{k}}=\frac{\lambda p}{m^{2}}\left(1-\theta\left(\frac{1}{m-1}-\frac{m}{k(k+1)}+1\right)\right)
$$

Since $k \leq m-1, m \geq 2$, and $\theta \leq 1$, the above term is always positive and therefore adding one more member to any cooperation with $k \leq m-1$ firms is always beneficial for each firm. As a result, a cooperation involving all $m$ firms (grand coalition) would naturally form in a market with $m$ symmetric single-product firms. 